\title{
Concession Bargaining
}

\section{An Experimental Comparison of Protocols and Time Horizons}

\begin{abstract}
We test experimentally whether dynamic interaction is crucial for concession bargaining. In our complete information bargaining experiments, two parties with asymmetric conflict payoffs try to agree how to share a commonly known pie by bargaining over a finite number of successive trials (agreement attempts). We compare the fully dynamic interaction to one less dynamic and one static protocol. In the quasi-dynamic protocol, later trials merely reveal that so far no agreement has been reached, and in the static protocol no feedback information is given about earlier trials. We find that neither conflict rate nor efficiency or inequality of agreements differ across protocols. Comparing different numbers of maximal trials shows that more trials render conflict more likely due to less concessions.

Keywords: concession bargaining, dynamic interaction, emotions, deadline, conflict, experiment.

JEL-Codes: C72, C78.
\end{abstract}

\section{Introduction}

Negotiations often unfold in time and are characterized by gradual concessions. When a party concedes this means that this party would now accept agreements that it so far would have rejected. Thus concessions try to prevent conflict in negotiations. Especially when conceding unfolds dynamically, parties may develop more realistic ideas of what others are willing to concede and moderate their own demands. 
Concession bargaining has already been theoretically analyzed by Zeuthen (1930), where prediction is closely related to the bargaining solution proposed by Nash (1950, 1953), as shown by Harsanyi (1956). However, the so-called Nash-bargaining solution appeals neither to time nor to concession-making. ${ }^{1}$ Other approaches to bargaining, e.g. Rubinstein (1982), rely on alternating offers in bargaining, but impose restrictions with profound consequences for the equilibrium outcome. ${ }^{2}$ This introduces our main research question: does it behaviorally matter whether concession-making is allowed to unfold in time? In trying to answer this question, we do not impose alternation but rather allow for independent choices along the way. This raises another question: ${ }^{3}$ does this naturally lead to alternation in conceding? Then we ask: does behavior change when we restrict feedback about earlier failed agreement attempts although such restrictions do not affect the strategic incentives?

Except for dynamic games, whose state variables determine the rules for future choice making, what matters strategically is how choices can be conditioned. Now conditioning choices as in sequential bargaining games are adequately captured by the normal form representation of such games. Thus, conditioning behavior can be studied experimentally by comparing the "cold" strategy method with the "hot" sequential play method (see, for example, Brandts and Charness, 2011, or the final section of Fischer and Güth, 2012). The strategy method is a convenient experimental method delivering more informative choice data but is also used in the field, e.g. when negotiating via delegates instructed by strategies specifying each imaginable contingency of how to behave (for an early study of bargaining through delegates, see Schotter et al., 2000). Such bargaining by delegates may be partly substituted by online negotiations, which render the bargaining process less influenced by emotions and tactics, e.g. those shaping concession-making.

However, the normal form of a truly dynamic negotiation can become excessively complex since strategy spaces grow exponentially in the number of available attempts for finding an agreement. We therefore only compare the truly dynamic game to versions 
in which timing is not important or reduced to mere conditioning. More specifically, we distinguish three bargaining protocols:

- Dynamically unfolding concession-making with feedback information about previous attempts via informing about the earlier demands by the other party described as "hot" due to possible strong emotional arousal when one party learns that the other party did not concede at all or only insufficiently, e.g. compared to the own former concession. Such emotional arousal may cause higher demand or lower concession levels in subsequent trials.

- Quasi-dynamic interaction maintaining an awareness that earlier agreement attempts have failed without, however, informing about the earlier demands by the other party - one can only infer that the other party's demand exceeds what is left after subtracting one's own demand. Thus, one is keenly aware, as in the fully dynamic protocol, of not yet having agreed - this protocol is described as "quasihot" as a party might experience some emotional arousal after learning that all previous agreement attempts have failed.

- Static interaction where parties, in the spirit of normal form bargaining games, choose independently complete behavioral plans prescribing, for any possible constellation in the course of concession bargaining, how much to concede. As a consequence, parties must imagine all possible cases of earlier failures in reaching an agreement, i.e. all concessions are made not knowing whether or not they will be needed - for this reason, this protocol is characterised as "cold".

Although we compare "hot" play versus "cold" strategy method only the latter two protocols capture the same game. The first presents a richer game allowing for conditioning not only on earlier failures but also on the actual demands leading to them and capturing the true dynamics and triggering possibly strong emotional and nervous arousal during the negotiation process. Moving from the dynamic to the static proto- 
col we gradually eliminate crucial aspects of dynamic bargaining in order to assess how relevant the negotiation dynamics are.

Recently Grimm and Mengel (2011) raised interest in the influence of emotions on negotiations. Building on Bosman et al. (2001), who showed that (self-reported) emotions strongly correlate with acceptance of ultimatum offers, Grimm and Mengel find that enforcing a break of about ten minutes before deciding whether (or not) to accept an ultimatum offer suffices to increase acceptance of low offers. Oechssler et al. (2015) make a similar observation in one of their treatments. Related evidence comes from research exploring the relevance of anger, as for example in Zizzo (2004, 2008). Surprisingly, the literature comparing ultimatum bargaining behavior of "hot" play and "cold" strategy choice, either finds no difference or that the strategy method strengthen fairness concerns (see Fischer and Güth, 2012).

Specifically, for the three protocols we expected the following effects: As quasidynamic interaction is more prone to emotional arousal than the static one, we predicted more conflict in the former. The truly dynamic interaction should trigger the strongest emotional arousa but also the best chances of successful coordination, e.g. as measured by lower efficiency due to anticonflict. ${ }^{4}$ Due to better coordination, efficiency of agreements is likely to be higher in the dynamic than in the other two protocols. ${ }^{5}$ We expected this effect to be stronger when finding an agreement at later trials. To explore this issue, we compared a short and a long deadline, the latter allowing for twice as many concessions before the deadline. While we expected emotions to remain unaffected by the time horizon, we predicted better coordinated demands, especially in the dynamic protocol.

Contrary to our expectations, crucial outcome characteristics like conflict ratio, efficiency and inequality of agreements do not depend on protocol. In our view, this is comforting for institutional design of bargaining and negotiation rules. Committees do not have to meet and reconvene frequently in order to reach an agreement via concession 
making, at least in situations of complete information. ${ }^{6}$ However, the time horizon affects the rate of conflict across protocols: the rate of conflict rises with the longer deadline.

All protocols rely on the strategic or ('non-cooperative') bargaining approach. As such they differ substantially from the early characteristic function bargaining experiments (see e.g. Sauermann, 1967) and the more recent ones of unstructured bargaining (see e.g. Anbarci and Feltovich, 2013, 2014). Whereas strategic bargaining appeals to methodological individualism - one tries to explain bargaining by individual choice behavior - the other traditions seem to suggest that subtle details are often unspecified in field settings. But there exist also field situations such as international negotiations on army control and environmental issues where detailed protocols are clearly specified before actually making concessions. In collective wage bargaining (e.g. Levinson, 1966) the more centralised negotiations as in Europe rely on stricter protocols than firm-level ones in the US (see Du Caju et al., 2008). Altogether none of the approaches is superior. Whereas less structured protocols often offer convenient shortcuts to find out stylized outcome effects, studies like ours focus on a detailed analysis of specific procedural details like who will concede when and how much. What we explore is nevertheless a crucial aspect of nearly all field cases, namely how to avoid an impasse when initial demands are too ambitious and when an agreement requires conceding.

Concessions in the spirit of the analysis by Zeuthen (1930) have also been experimentally explored by Bolton and Karagözoğlu (2016). They analyze the influence of relative performance of players in a real effort task on initial demands and the subsequent demand levels. Instead of an asymmetry induced by differences in relative performance, we impose exogenously asymmetric conflict payoffs.

The related study by Felli et al. (forthcoming) also captures concession-making in bilateral bargaining and also varies the maximal number of concessions. However, there are three major differences:

(a) whereas Felli et al. only use the strategy method, our study explores also dynamic 
bargaining via two additional protocols but with less focus on experience;

(b) Felli et al. implement ultimatum bargaining meaning that the responder determines only the range of acceptable offers and that the proposer is the residual claimant, ${ }^{7}$

(c) the demand game (see Nash, 1953), on which our study is based, does not rely on such different roles - in our setup both parties collect their agreement demands. Instead we analyze asymmetry via exogenously given asymmetric conflict payoffs.

Since we investigate two sequential protocols (one where one concedes being aware that the earlier attempts have failed and one where one knows all the failed past proposals), we can assess whether and how conceding in the light of failed past agreements matters. By (a) we thus also contribute to the fundamental debate in game theory whether the normal form of a game captures all strategically relevant aspects what game-theoretically justifies using the strategy method (see Neumann and Morgenstern, 1944 and more recently Kohlberg and Mertens, 1986).

The importance of aspect (b) can be illustrated by an equilibrium analysis of both games, the demand game and the ultimatum game. ${ }^{8}$ The former is characterized by a typically large multiplicity of strict equilibria (unilateral deviations from such equilibria result in a loss) whereas the equilibria of the ultimatum game are weak (the responder's payoff only changes when accepting or rejecting the actual offer but not when reacting to other offers). Solving the demand game uniquely requires a theory of equilibrium selection (see Nash, 1950, and more generally Harsanyi and Selten, 1988) whereas the ultimatum game can be solved by once repeated elimination of weakly dominated strategies. Finally agreeing to share less than available, i.e. the so-called anticonflict as an off-equilibrium phenomenon, is excluded by the ultimatum game.

Asymmetric conflict payoffs allow to assess whether parties, for example when sharing equally, rely on the agreement surplus (the pie minus the conflict payoffs) or the pie, 
e.g. when considering individual conflict payoffs as purely counterfactual and therefore negligible opportunities. For the answer it may matter which bargaining protocol one implements. Altogether there is a story overlap in the general research topic of both studies, namely concession-making, and partly in the elicitation method (see also the comparison of specific results in Felli et al., forthcoming). On the other hand, the specific hypotheses to be tested experimentally, differ considerably due to the very different bargaining rules and protocols. Both studies together hopefully allow a more reliable assessment of concession-making in bilateral bargaining.

\section{The bilateral bargaining problem and the protocols}

Two parties or players 1 and 2 can divide 650 points, convertible to money at a known exchange rate, with commonly known conflict payoffs of 175 points for one player and 25 for the other. In all protocols bargaining is based on hierarchically ordered demands $d_{i}^{t}$ in the sense of $d_{i}^{t+1} \leq d_{i}^{t}$ for $i=1,2$. If $d_{i}^{t+1}<d_{i}^{t}$, i.e. if the demand decreases from trial $t$ to $t+1$, we speak of a concession $k$ by player $i$ in trial $t+1$ of size $k_{i}^{t+1}=$

$d_{i}^{t}-d_{i}^{t+1}$. Correspondingly, whenever $d_{i}^{t+1}=d_{i}^{t}$, player $i$ does not concede. If neither party concedes, bargaining ends in conflict - see Felli et al. (forthcoming) for a study comparing this rule of ending the game with one ruling out early conflict before reaching the deadline or maximum number of trials $T$.

The intuition of such rule is that when neither party concedes in situations of well prepared bargaining behavior such as, for instance, among nations as in collective wage bargaining, there seems to be no mutually satisfactory agreement, that discourages any further agreement attempts. In our view, continuing to negotiate after no concession is more typical of bazar-like bargaining situations rather than of well planned negotiations where each further trial is usually rather costly.

What we compare for all three protocols, is the number of trials $t=1, \cdots, T$, specif- 
ically $T=3$ and $T=5$. In case of $T=3$ there can be at most two concessions, in case of $T=5$ at most four.

In the static protocol $\mathbf{S}$ players $i=1,2$ determine their demand vectors

$$
\mathbf{d}_{i}=\left(d_{i}^{1}, d_{i}^{2}, \cdots, d_{i}^{T}\right) \text { with } d_{i}^{t+1} \leq d_{i}^{t} \text { for all } t<T
$$

independently and simultaneously before play. If for all $\tau<t$ it holds that $d_{1}^{\tau}+d_{2}^{\tau}>650$ but $d_{i}^{\tau+1}<d_{i}^{\tau}$ for at least one player $i=1,2$, an agreement is reached in trial $t$ when $d_{1}^{t}+d_{2}^{t} \leq 650$ with each player receiving what he demanded. ${ }^{9}$ If, however, $d_{1}^{T}+d_{2}^{T}>650$ or, in case of $t<T, d_{1}^{t+1}=d_{1}^{t}$ and $d_{2}^{t+1}=d_{2}^{t}$ (i.e. no concession from either party) bargaining ends with conflict and players receive their respective conflict payoff $c_{i}$.

If at any time a pair reached trial $t$ but is unable to agree at $t$, there will only be a later agreement attempt at $t+1$ if at least one player $i=1,2$ made an at least minimal concession $\left(d_{i}^{t}<d_{i}^{t+1}\right)$. To avoid trivial concessions which are too small to qualify as a significant sacrifice, we required minimal concessions of 25 points, a prominent but significant share, about $3.85 \%$, of the available pie.

We experimentally enforce Zeuthen's (1930) model of concession bargaining which appeals to a gradual process, where at each trial either at least one party makes a concession, accepts the terms offered by the other party or quits. Such concessions are not only attempts to align total demand with what is available but also necessary for preventing "early" conflict.

Another aspect concerns anti-conflict, i.e. agreement in trials $i=1,2, \cdots, T$ with $d_{i}^{t}+d_{2}^{t}<650$. This never occurs in equilibrium. Here, we simply assume that $650-d_{1}^{t}-d_{2}^{t}$ is lost for the two interacting parties.

The quasi-dynamic or positional-order protocol $\mathbf{P}$ is identical to protocol $\mathrm{S}$ in terms the game structure and the minimal concession. The only difference relates to information on the outcome of previous attempts to reach an agreement. In protocol S, 
players $i=1,2$ do not know when stating $d_{i}^{t+1}$ that earlier attempts have failed (but are aware that such demands only matter when previous attempts have failed), whereas in protocol P they know this. Thus, protocol P differs from protocol S by asking for later demands only when they are needed. More specifically, demand $d_{i}^{t+1}$ is only elicited from $i$ when there is no "earlier" agreement or conflict due to no concession on both sides, i.e. $d_{1}^{\tau}+d_{2}^{\tau}>650$ and $d_{1}^{\tau}+d_{2}^{\tau}<d_{1}^{\tau-1}+d_{2}^{\tau-1}$ for all $\tau<t$. In other words: the comparison of protocol S and P confronts the "cold" strategy method (protocol S) with the (quasi-) "hot" sequential method in a richer setting than usual. Strategically, the two protocols implement the same game.

The third, truly dynamic protocol $\mathbf{D}$, represents a different and richer game, allowing for all sorts of path dependency like alternating in concession-making, reciprocity in sizing one's concession, etc. The amount of minimal concessions is the same as in protocols $\mathrm{S}$ and $\mathrm{P}$. As in protocol $\mathrm{P}$ players $i=1,2$ only have to choose $d_{i}^{t+1}$ in trial $t+1$ in case of no earlier agreement. However, unlike in protocol $\mathrm{P}$, players $i=1,2$ also know all earlier demands $d_{1}^{\tau}, d_{2}^{\tau}$ for $\tau \leq t$ and why they led to another trial in $t+1$. This allows for stronger emotional arousal but at the same time also for better coordination than in the other protocols.

Altogether we rely on a $2 \times 3$ factorial design, $T=3$ versus $T=5$ as well as protocols S, P, and D. All six treatments have a large multiplicity of strict agreement equilibria whose agreement demands $\left(d_{1}^{t^{*}}, d_{2}^{t^{*}}\right)$ satisfy $d_{1}^{t^{*}}+d_{2}^{t^{*}}=650$ and with $i$ 's demand exceeding the conflict payoff $c_{i}$ of player $i=1,2$. To select among the efficient equilibria one can rely on the bargaining solution of Nash $(1950,1953)$ predicting

$$
d_{i}^{t}=c_{i}+\frac{650-200}{2}=c_{i}+225
$$

for $c_{i} \in\{25,175\}$. Another relevant focal point, in addition to the Nash bargaining solution payoffs of 250 and 400 with equal agreement dividends of 225 , is the equal split 
with 325 each, which leads to very unequal agreement dividends.

Based on existing experimental evidence (Fischer et al., 2007; Anbarci and Feltovich, 2013) we expect the vast majority of agreements to lie between these two benchmarks. Despite D differing from $\mathrm{S}$ and $\mathrm{P}$, incentives are identical. The only difference is that D has a considerably larger space of conditional strategies. Overall, while theoretically there should be no effect of protocol and maximal number of concession attempts, due to emotional arousal, behaviorally it should matter.

There also exists a multiplicity of inefficient conflict equilibria, with both parties offering the other at most its conflict payoff. However, related experimental evidence, such as in Fischer et al. (2007) and Anbarci and Feltovich (2013) suggest that this is of only little behavioral relevance as one usually will strive for an agreement.

\section{Experiment}

The experiment has a $3 \times 2$ design: we have explored the protocols $\mathrm{S}, \mathrm{P}$, and $\mathrm{D}$ between subjects, and $T \in\{3,5\}$ within subjects but with the order " $T=3$ first, $T=5$ second"

or " $3 \rightarrow 5$ ", respectively reversed as " $5 \rightarrow 3$ ", implemented between subjects. ${ }^{10}$ For each treatment out of six, we ran three sessions with two matching groups of eight participants each. We therefore have observations from a total of 288 participants, with twelve independent matching groups per combination of protocol with $T$. For example, for combination $\mathrm{S}$ and $T=3$ we have six independent matching groups from $\mathrm{S} 3 \rightarrow 5$ and another six from $\mathrm{S} 5 \rightarrow 3$.

Instructions were read aloud to provide common knowledge of the rules of the game, e.g. of the asymmetry in conflict payoffs (see online appendix A). After that participants had to answer control questions concerning the rules of the game, including the effect of neither party making a concession (see online appendix B).

Within each session we once repeated both treatment combinations in order to check 
for effects of experience in some minimal way. ${ }^{11}$ More specifically, participants in Sessions $\mathrm{S}$ of $3 \rightarrow 5$ first played two rounds of protocol $\mathrm{S}$ with $T=3$, followed by two rounds of protocol S with $T=5$. Rematching between rounds used a stranger design. ${ }^{12}$ Throughout a session a participant kept the same conflict payoff $c_{i}$ and the outcome of every round was paid.

All sessions were conducted in the experimental laboratory of [name of institution removed]. Recruitment was among students at the two local universities and relied on ORSEE (Greiner, 2015), the experimental software relied on zTree (Fischbacher, 2007). Online appendix D contains the screenshots of the experiment. On average sessions lasted for 50 minutes including admission and payment. Participants earned on average $16.44 €$, including a show up fee of $5 € . .^{13}$

Of the 288 participants about $51.7 \%$ were female, and average age was 24 years (min. 19, max. 34). Everyone either was a student or had just finished university. Only $2.8 \%$ were students of economics. ${ }^{14}$ With respect to these and other (self-reported) sociodemographic characteristics there were no differences between protocols. ${ }^{15}$ We therefore did not fall victim to an unfortunate sample selection.

\section{Main findings}

With respect to the most crucial outcome variables like frequency of conflict, efficiency of agreement as measured by the sum of agreement demands and the (in)equality of agreement dividends, invariance applies to all three protocols.

Result 1: For each horizon $T$ individually, and for both combined, the protocol (S, $\mathrm{P}$, or D) does not significantly affect frequency of conflict, efficiency or (in)equality of agreements.

Note we measure inequality as the difference in the payoff of the subject with $c=175$ minus that of the participant with $c=25$. Qualitatively results do not change if we use 
the absolute value of the difference.

Figure 1 shows the distributions of these variables separately for every combination of protocol and $T$. Table 1 illustrates the results of rank-sum tests, based on the distributions of averages over all rounds per independent matching group. Despite, for example, there being higher efficiency of agreements in $\mathrm{D}$ compared to $\mathrm{S}$ and $\mathrm{P}$ when $T=3$, all differences between protocols are insignificant. Since we perform three pairs of protocol comparisons, we rely on the acceptance thresholds adjusted according to a $5 \%$ false discovery rate criteria of Benjamini and Hochberg (1995). ${ }^{16}$
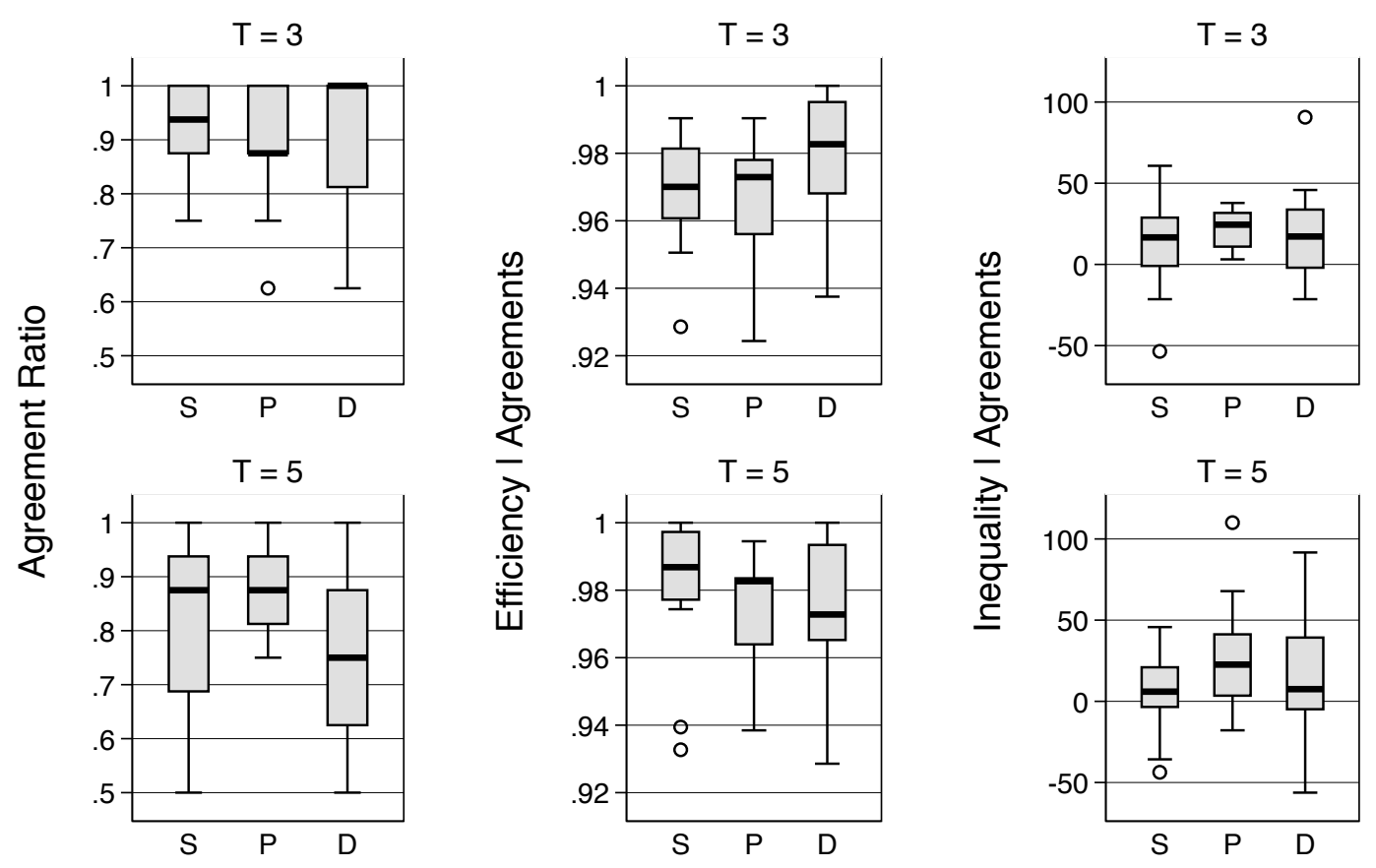

Figure 1: Agreement ratio, efficiency and inequality by protocol and time horizon $T$

Notes: Efficiency and inequality are defined as $\left(d_{25}^{t}+d_{175}^{t}\right) / 650$ and $d_{175}^{t}-d_{25}^{t}$ respectively when agreement is reached at trial $t$. Each observation is the mean value at the group level. 
Table 1: Rank-sum tests on agreement ratio, efficiency and inequality by protocol

Agreement Ratio

\begin{tabular}{|c|c|c|c|c|c|c|c|c|c|c|}
\hline \multirow[b]{2}{*}{ Protocol } & \multirow[b]{2}{*}{$(\mathrm{N})$} & \multicolumn{3}{|l|}{$T=3$} & \multicolumn{3}{|l|}{$T=5$} & \multicolumn{3}{|c|}{ Combined } \\
\hline & & Mean & $\mathrm{P}$ & D & Mean & $\mathrm{P}$ & D & Mean & $\mathrm{P}$ & D \\
\hline $\mathrm{S}$ & $(12)$ & 0.9271 & 0.5689 & 0.9490 & 0.8021 & 0.4123 & 0.4600 & 0.8646 & 0.6343 & 0.3599 \\
\hline $\mathrm{P}$ & (12) & 0.8958 & & 0.6610 & 0.875 & & 0.0722 & 0.8854 & & 0.1206 \\
\hline $\mathrm{D}$ & $(12)$ & 0.9063 & $p$-value & ranksum test & 0.75 & $p$-value & ranksum test & 0.8281 & $p$-value & ranksum test \\
\hline
\end{tabular}

Efficiency |Agreement

\begin{tabular}{|c|c|c|c|c|c|c|c|c|c|c|}
\hline \multirow[b]{2}{*}{ Protocol } & \multirow[b]{2}{*}{$(\mathrm{N})$} & \multicolumn{3}{|l|}{$T=3$} & \multicolumn{3}{|l|}{$T=5$} & \multicolumn{3}{|c|}{ Combined } \\
\hline & & Mean & $\mathrm{P}$ & $\mathrm{D}$ & Mean & $\mathrm{P}$ & $\mathrm{D}$ & Mean & $\mathrm{P}$ & $\mathrm{D}$ \\
\hline $\mathrm{S}$ & (12) & 0.9688 & 0.7947 & 0.1056 & 0.9806 & 0.1933 & 0.3842 & 0.9746 & 0.2854 & 0.9310 \\
\hline $\mathrm{P}$ & (12) & 0.9652 & & 0.1056 & 0.9747 & & 0.7073 & 0.9697 & & 0.6649 \\
\hline $\mathrm{D}$ & $(12)$ & 0.9787 & $p$-value & ranksum test & 0.9751 & $p$-value & ranksum test & 0.9758 & $p$-value & ranksum test \\
\hline
\end{tabular}

Inequality |Agreement

\begin{tabular}{|c|c|c|c|c|c|c|c|c|c|c|}
\hline \multirow[b]{2}{*}{ Protocol } & \multirow[b]{2}{*}{$(\mathrm{N})$} & \multicolumn{3}{|l|}{$T=3$} & \multicolumn{3}{|l|}{$T=5$} & \multicolumn{3}{|c|}{ Combined } \\
\hline & & Mean & $\mathrm{P}$ & $\mathrm{D}$ & Mean & $\mathrm{P}$ & $\mathrm{D}$ & Mean & $\mathrm{P}$ & $\mathrm{D}$ \\
\hline $\mathrm{S}$ & (12) & 12.26 & 0.2985 & 0.6860 & 4.56 & 0.0781 & 0.8397 & 9.02 & 0.0833 & 0.4024 \\
\hline $\mathrm{P}$ & (12) & 22.38 & & 0.5441 & 28.99 & & 0.2253 & 26.05 & & 0.4356 \\
\hline $\mathrm{D}$ & (12) & 20.11 & $p$-value & ranksum test & 12.5 & $p$-value & ranksum test & 17.61 & $p$-value & ranksum test \\
\hline
\end{tabular}

Notes: $p$-values are two-sided. Each observation is the mean value at the group level. 
We ran further robustness tests, which all confirm this null-result. We qualitatively observe identical results if we only look at data (a) from the first two rounds, (b) the last two rounds, (c) the first and third round, (d) the second and fourth round. The same holds for independent first round data per bargaining pair. According to Kruskal-Wallis tests the distributions of agreed payoffs in the first round do not differ across protocols. Parametric methods (controlling for the panel structure) also confirm our results (see Table E.1 of online appendix).

Thus, conjectures of higher agreement rate in $\mathrm{S}$ rather than $\mathrm{P}$ due to emotional arousal and the higher efficiency in $\mathrm{D}$ than in $\mathrm{S}$ and $\mathrm{P}$ (especially when $T=5$ ) are not confirmed. As expected, the level of inequality for most agreeing pairs lies between 0 and 150, however values of or near 0 are frequent. Remember that the expected difference between payoffs is 0 for an equal split and 150 for the mid-point (Nash) prediction. Overall, the equal split is considerably more focal than the Nash bargaining solution. This outcome seems focal also in so-called 'unstructured bargaining' (see Anbarci and Feltovich, 2013, 2014).

Protocol effects are unobserved, but how about the number of possible concessions $(T=3$ versus $T=5)$ ? Actually, here we find a significant effect for one of the outcome variables, namely the frequency of conflict.

Result 2: The frequency of conflict increases with time horizon, $T$.

With the combined data, the difference in the rate of agreement is significant (twosided $p=0.0076$ with the sign-ranked test and $p<0.01$ for the dummy variable of $T=5$ with the logit regression; see Table 2 and the third column of Table E. 1 of online appendix. The corresponding box-plot graphs are provided with Figure E.1), though the differences are insignificant for each protocol individually.

Surprisingly, efficiency of agreements does not significantly change with the number of available trials $T$. 
Table 2: Sign-rank tests on agreement ratio, efficiency and inequality by time horizon $T$

\begin{tabular}{|c|c|c|c|c|c|c|c|}
\hline \multirow[b]{3}{*}{ Protocol } & \multirow[b]{3}{*}{$(\mathrm{N})$} & \multicolumn{3}{|c|}{ Agreement Ratio } & \multicolumn{3}{|c|}{ Efficiency |Agreement } \\
\hline & & \multicolumn{2}{|l|}{ Mean } & \multirow{2}{*}{$\begin{array}{l}p \text {-value } \\
\text { signrank }\end{array}$} & \multicolumn{2}{|l|}{ Mean } & \multirow{2}{*}{$\begin{array}{l}p \text {-value } \\
\text { signrank }\end{array}$} \\
\hline & & $T=3$ & $T=5$ & & $T=3$ & $T=5$ & \\
\hline $\mathrm{S}$ & (12) & 0.9271 & & & 0.9688 & 0.9806 & 0.1361 \\
\hline $\mathrm{P}$ & $(12)$ & 0.8958 & 0.8750 & 0.3416 & 0.9652 & 0.9747 & 0.2393 \\
\hline $\mathrm{D}$ & $(12)$ & 0.9063 & 0.7500 & 0.0523 & 0.9787 & 0.9751 & 0.5561 \\
\hline Combined & $(36)$ & 0.9097 & 0.8090 & 0.0076 & 0.9709 & 0.9768 & 0.1817 \\
\hline
\end{tabular}

\begin{tabular}{lllll} 
& & \multicolumn{3}{l}{ Inequality $\mid$ Agreement } \\
\cline { 3 - 4 } & & \multicolumn{2}{l}{ Mean } & p-value \\
\cline { 3 - 4 } Protocol & $(\mathrm{N})$ & $T=3$ & $T=5$ & signrank \\
\hline $\mathrm{S}$ & $(12)$ & 12.26 & 4.56 & 0.5303 \\
$\mathrm{P}$ & $(12)$ & 22.38 & 28.99 & 0.9375 \\
$\mathrm{D}$ & $(12)$ & 20.11 & 12.50 & 0.6379 \\
Combined & $(36)$ & 18.25 & 15.35 & 0.5043 \\
\hline
\end{tabular}

Notes: $p$-values are two-sided. Each observation is at the mean at the group level.

Result 3: Efficiency of agreements does not increase significantly with time horizon.

Whereas Result 1 was expected, Results 2 and 3 are surprising. A longer horizon allows obviously for more attempts to find an agreement, and to fine-tune an agreement by trying to render it more efficient. The contrary effects stated by Results 2 and 3 could be due to more emotional arousal when concessions can unfold more over time. A more detailed analysis of the data might help to clarify this.

\section{Detailed analysis of behavior}

\subsection{Different endpoints of the bargaining process}

Given the invariance of bargaining protocol, are there any differences in the bargaining process, which average out over the entire game? First we check whether there are different reasons for ending up with conflict or different kinds of agreements across 
protocols and horizon $T$. There are four possible outcomes: (a) efficient agreement, (b) anti-conflict agreement, (c) conflict due to no concessions and (d) conflict due to insufficient concessions. An agreement is efficient when $d_{1}^{t}+d_{2}^{t}=650$ and there is anticonflict agreement if $d_{1}^{t}+d_{2}^{t}<650$. Conflict due to no concessions occurs when at one point both players refuse to concede. Conflict due to insufficient concessions arises when the pair was unable to reach an agreement up to deadline $T .{ }^{17}$

Figure 2 shows the cumulative incidence of the four outcomes for each protocol and $T$ over trial. ${ }^{18}$ The mean values reported in Table 3 are the relative frequencies of the four outcomes when the game ends, thus they correspond the bars for $t=T$ in Figure 2. With an acceptance threshold adjusted according to the false discovery rate of $5 \%$ we find no significant difference between protocols in any of the final outcomes. Without adjustment, i.e. at a 5\% threshold, the results of the Wilcoxon sign-rank test for anticonflict agreement ratios show a significantly higher result in $\mathrm{P}$ than in $\mathrm{S}(p=0.0463$, two-sided $)$ and in $\mathrm{P}$ than in $\mathrm{D}(p=0.0392$, two-sided $)$ when $T=5$. However, these $p$ values are no longer significant if the thresholds are adjusted for the multiple-comparison test: $0.0463>0.05 \cdot \frac{2}{3}$ and $0.0392>0.05 \cdot \frac{1}{3}$.

If we compare ratios of outcomes between $T=3$ and $T=5$ in each protocol, we observe a consistently higher ratio of anti-conflict agreement, a lower ratio of conflict due to no concession and a higher ratio of conflict due to insufficient concessions when $T=3$. As Table 3 indicates, some of the differences are statistically significant at the adjusted acceptance threshold. Even if we pool the data from all protocols, the differences in anti-conflict agreements and conflict due to insufficient concessions are significant. It seems that pure anticipation of only two rather than four concessions triggers attempts of either being tough by making no or little concession or avoiding to learn what the other party requires minimally. On the other hand, there is no significant difference in efficient agreements between $T=3$ and $T=5$. Thus, the drop in agreement rate when $T=5$, observed in Result 2, is primarily a drop in anti-conflict agreements, which is 

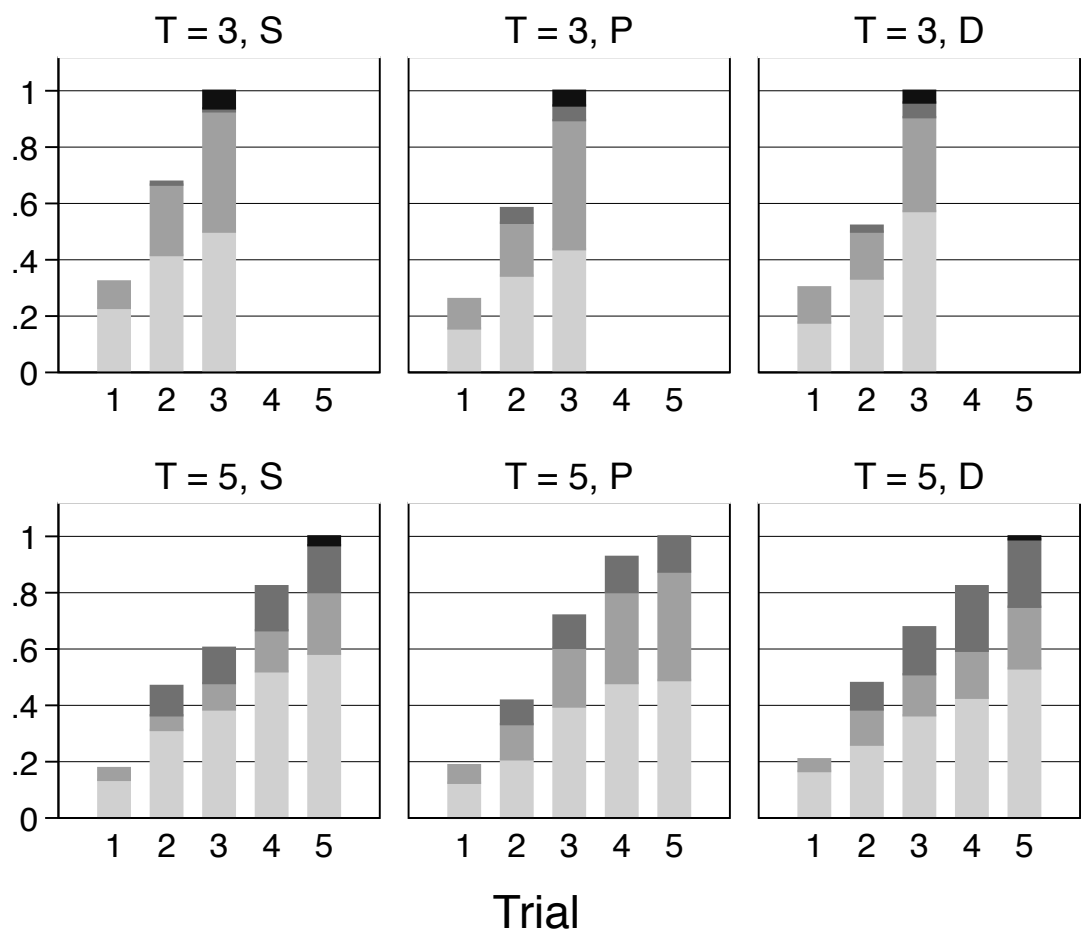

Trial

\section{Efficient agreement}

Anti-conflict agreement No concession conf. Insufficient concession conf.

Figure 2: Cumulative incidence of types of outcomes 
accompanied by an increase in no-concession conflicts.

Table 3: Sign-rank tests on efficient agreement, anti-conflict agreement, no concession conflict and insufficient concession conflict by time horizon $T$

\begin{tabular}{|c|c|c|c|c|c|c|c|c|}
\hline \multirow[b]{3}{*}{ Protocol } & \multicolumn{4}{|c|}{ Rate of Efficient Agreements } & \multicolumn{4}{|c|}{ Rate of Anti-Conflict Agreements } \\
\hline & \multicolumn{2}{|l|}{ Mean } & \multirow{2}{*}{$(N)$} & \multirow{2}{*}{$\begin{array}{l}p \text {-value } \\
\text { signrank }\end{array}$} & \multicolumn{2}{|l|}{ Mean } & \multirow{2}{*}{$(N)$} & \multirow{2}{*}{$\begin{array}{l}p \text {-value } \\
\text { signrank }\end{array}$} \\
\hline & $T=3$ & $T=5$ & & & $T=3$ & $T=5$ & & \\
\hline S & 0.5000 & 0.5833 & $(12)$ & 0.2039 & 0.4271 & 0.2188 & $(12)$ & 0.0141 \\
\hline $\mathrm{P}$ & 0.4375 & 0.4896 & $(12)$ & 0.4503 & 0.4583 & 0.3854 & $(12)$ & 0.4067 \\
\hline D & 0.5729 & 0.5313 & (12) & 0.3808 & 0.3333 & 0.2188 & (12) & 0.0864 \\
\hline \multirow[t]{3}{*}{ Combined } & 0.5035 & 0.5347 & $(36)$ & 0.4541 & 0.4063 & 0.2743 & $(36)$ & 0.0062 \\
\hline & \multicolumn{4}{|c|}{ Rate of No Concession Conflict } & \multicolumn{4}{|c|}{ Rate of Insufficient Concession Conf. } \\
\hline & \multicolumn{2}{|l|}{ Mean } & \multirow{2}{*}{$(N)$} & \multirow{2}{*}{$\begin{array}{l}p \text {-value } \\
\text { signrank }\end{array}$} & \multicolumn{2}{|l|}{ Mean } & \multirow{2}{*}{$(N)$} & \multirow{2}{*}{$\begin{array}{l}p \text {-value } \\
\text { signrank }\end{array}$} \\
\hline Protocol & $T=3$ & $T=5$ & & & $T=3$ & $T=5$ & & \\
\hline $\mathrm{S}$ & 0.0104 & 0.1667 & $(12)$ & 0.0095 & 0.0625 & 0.0313 & (12) & 0.1797 \\
\hline $\mathrm{P}$ & 0.0521 & 0.1250 & (12) & 0.0519 & 0.0521 & 0.0000 & (12) & 0.0462 \\
\hline $\mathrm{D}$ & 0.0521 & 0.2396 & (12) & 0.0137 & 0.0417 & 0.0104 & $(12)$ & 0.2965 \\
\hline Combined & 0.0382 & 0.1771 & $(36)$ & 0.0001 & 0.0521 & 0.0139 & $(36)$ & 0.0116 \\
\hline
\end{tabular}

Notes: $p$-values are two-sided. Each observation is the mean at the group level.

To check whether this increase in no-concession conflicts is a mere consequence of increased opportunity, we looked at the evolution of outcomes as illustrated in Figure 2. The patterns over time look very similar for the three protocols, which confirms Result 1 of no effect of protocol. With respect to early break up, for $T=5$ the likelihood of a pair breaking up early is already large at Trials 2 and 3 . Thus, it appears that a larger time horizon renders participants more stubborn.

We therefore compared the likelihood that a player refuses to concede. The first and second columns of Table 4 report the results of logit models in which, in a trial $t>1$, the dependent variable is one if the player's current demand level is the same with that in the previous trial, otherwise zero. The explanatory variables are a dummy for time horizon $(T=5)$, dummies for protocols $\mathrm{P}$ and $\mathrm{D}$, number of trials, dummies for cases where the previous demand was 325 points and between 326 and 350 points, order of 
play, and round number. Regression (1) is for players with low conflict payoff and (2) for high conflict payoff players. As for Protocol S, we use observations when the player is still bargaining in order to be consistent with the data of other protocols.

The dummy variable $T=5$ is significantly positive for both Regressions (1) and (2), hence players are less likely to concede in case of $T=5$, irrespective of conflict payoff. ${ }^{19}$ Result 4: The increase in time horizon makes both types of players less likely to concede and increases the chance of an early break up.

We also find that

(a) for low conflict payoff players, conceding is more likely when players only know that they are still bargaining as shown by the significantly negative dummy variable for protocol P;

(b) both players are neither more nor less likely to stop conceding as the number of trials increases;

(c) both players tend to stop conceding at 325, the equal split demand;

(d) only high conflict payoff players stop conceding at a level slightly higher than 325 , specifically between 326 and $350 ;{ }^{20}$

(e) high conflict payoff players are less likely to stop conceding in the treatment $5 \rightarrow 3$;

(g) high conflict payoff players are more likely to stop conceding as the number of rounds increases.

\subsection{Concession levels and demand levels}

We also checked the concession sizes of both types of players. We define a concession $k^{t}$ as we did in Section 2. While $32.9 \%$ of all decisions made from the second trial onward (and before finishing bargaining for Protocol S) are "no concession", the rate of 
Table 4: Logistic regressions on "no concession" and linear regressions on "concession size"

\begin{tabular}{|c|c|c|c|c|}
\hline \multirow[t]{2}{*}{ Regression } & (1) & $(2)$ & $(3)$ & $(4)$ \\
\hline & \multicolumn{2}{|c|}{ No concession } & \multicolumn{2}{|c|}{ Concession $k_{i}^{t} \mid k_{i}^{t}>0$} \\
\hline Variables & $c_{i}=25$ & $c_{i}=175$ & $c_{i}=25$ & $c_{i}=175$ \\
\hline$T=5$ & $\begin{array}{c}0.754^{* * *} \\
(0.218)\end{array}$ & $\begin{array}{c}0.747^{* * *} \\
(0.226)\end{array}$ & $\begin{array}{c}-6.646^{* * *} \\
(2.092)\end{array}$ & $\begin{array}{c}-15.04^{* * *} \\
(2.813)\end{array}$ \\
\hline Protocol P & $\begin{array}{c}-0.847^{* *} \\
(0.351)\end{array}$ & $\begin{array}{l}-0.277 \\
(0.363)\end{array}$ & $\begin{array}{l}-6.712^{*} \\
(3.667)\end{array}$ & $\begin{array}{l}-12.82^{*} \\
(7.365)\end{array}$ \\
\hline Protocol D & $\begin{array}{l}-0.355 \\
(0.343)\end{array}$ & $\begin{array}{l}-0.285 \\
(0.372)\end{array}$ & $\begin{array}{l}-4.805 \\
(3.765)\end{array}$ & $\begin{array}{l}-9.800 \\
(7.449)\end{array}$ \\
\hline Trial & $\begin{array}{l}-0.207^{*} \\
(0.123)\end{array}$ & $\begin{array}{l}-0.175 \\
(0.127)\end{array}$ & $\begin{array}{c}0.959 \\
(1.203)\end{array}$ & $\begin{array}{l}1.706 \\
(1.652)\end{array}$ \\
\hline$d_{i}^{t-1}=325$ & $\begin{array}{c}2.615^{* * *} \\
(0.267)\end{array}$ & $\begin{array}{c}3.594^{* * *} \\
(0.328)\end{array}$ & $\begin{array}{c}-18.47^{* * *} \\
(2.363)\end{array}$ & $\begin{array}{c}-24.20^{* * *} \\
(3.147)\end{array}$ \\
\hline $325<d_{i}^{t-1} \leq 350$ & $\begin{array}{c}0.226 \\
(0.302)\end{array}$ & $\begin{array}{c}0.790^{* * *} \\
(0.276)\end{array}$ & $\begin{array}{c}-17.10^{* * *} \\
(2.830)\end{array}$ & $\begin{array}{c}-22.43^{* * *} \\
(6.105)\end{array}$ \\
\hline $5 \rightarrow 3$ & $\begin{array}{l}-0.341 \\
(0.288)\end{array}$ & $\begin{array}{c}-0.624^{* *} \\
(0.301)\end{array}$ & $\begin{array}{l}-3.241 \\
(3.029)\end{array}$ & $\begin{array}{l}-1.538 \\
(6.028)\end{array}$ \\
\hline Round & $\begin{array}{l}-0.0689 \\
(0.0934)\end{array}$ & $\begin{array}{l}0.213^{* *} \\
(0.0995)\end{array}$ & $\begin{array}{l}-1.467 \\
(0.917)\end{array}$ & $\begin{array}{l}-1.869 \\
(1.196)\end{array}$ \\
\hline Constant & $\begin{array}{c}-1.203^{* *} \\
(0.518)\end{array}$ & $\begin{array}{c}-1.955^{* * *} \\
(0.542)\end{array}$ & $\begin{array}{c}61.73^{* * *} \\
(5.184)\end{array}$ & $\begin{array}{c}73.15^{* * *} \\
(7.940)\end{array}$ \\
\hline Observations & 847 & 847 & 555 & 582 \\
\hline Number of subjects & 141 & 141 & 117 & 110 \\
\hline Number of groups & 36 & 36 & 36 & 36 \\
\hline
\end{tabular}

Notes: Each observation is the outcome per period per subject. For Protocol S, we exclude observations of pairs having finished bargaining. The regressions are three-level mixed models with random intercepts at both the session and the subject-within-session levels. The dependent variable "No concession" $=1$ if $d_{i}^{t}=d_{i}^{t-1}$, otherwise 0 . The dummy variable " $d_{i}^{t-1}=325$ " [" $325<d_{i}^{t-1} \leq 350$ "] $=1$ if the player demanded 325 points [between 326 and 350 points] in the previous trial. The dummy variable " $5 \rightarrow 3$ " is equal to 1 if $T=5$ in the first two rounds, otherwise 0. Standard errors in parentheses. Significance levels: ${ }^{* * *} p<0.01,{ }^{* *} p<0.05,{ }^{*} p<0.1$. 
minimum concessions 25 is $43.3 \%$. Since the minimum concession is modal (see Figure E.2 of online appendix), 25 points seems to be a binding constraint as planned. ${ }^{21}$

The third and fourth columns of Table 4 give the linear regression results of concession size when conceding. We use the same dependent variables with the logistic regressions on "no concession". The dummy variable $T=5$ is significantly negative for both Regressions (3) and (4), hence players of any conflict payoff concede fewer amounts when $T=5$.

Result 5: The increase in time horizon makes both types of players concede smaller amounts.

To summarize Results 4 and 5, the longer time horizon makes players more likely to stop conceding and, if they concede, to do so by smaller amounts. Another finding is that both players tend to reduce concession size when their demand levels are between 325 and 350 points. The order of play is significant only for "no concession" and high conflict payoff.

Finally we checked the demand levels of both conflict payoffs. The first and second columns of Table 5 report the regression results of demand level, number of trials, a dummy for time horizon $(T=5)$, dummies for protocols $\mathrm{P}$ and $\mathrm{D}$, interactions of these variables, order of play, and round number for each type of player. For protocol S, we use the data of only players who are still in the bargaining process. Figure E.4 of online appendix contains the corresponding diagrams. We find that

(a) low conflict payoff players increase their initial demands when horizon $T$ is larger as shown by the significantly positive dummy variable $T=5$ for players with low conflict payoff;

(b) less concessions when time horizon $T$ is large as implied by the significantly positive coefficient for the interaction between number of trials and time horizon;

(c) for high conflict payoff players, the initial level of demand is higher when players 
can see the demand levels of the opponent, although the concession size in the subsequent trials is larger, as implied by the significantly positive dummy for protocol $\mathrm{D}$ and the significantly negative interaction between number of trials and protocol $\mathrm{D}$

(d) for low conflict payoff players, concession size is larger when the players only know that they are still bargaining as shown by the significantly positive interaction between number of trials and protocol P;

(e) high conflict payoff players increase their demand with experience as the significantly positive round variable indicates.

Finding (b), that concession size is smaller for $T=5$, can be attributed to Results 4 and 5. According to finding (c), high conflict payoff players increase their initial demand by $26.31-5.592 \approx 20.72$, but concede approximately 5.59 more in each trial, hence they reach almost the same demand level as players in the other protocols at the 5th trial.

Our prior was that players in protocol D are more likely to experience emotional arousal as the game unfolds, that may cause higher demand or lower concession levels. If this were true, one should observe no increase in the initial demand levels and smaller concession sizes in subsequent trials. This pattern is rather different to what is actually observed. So emotions did not play a significant role.

Our results are more in line with the hypothesis that participants use their initial demand to influence the other player's behavior, i.e. that demand levels are signaling toughness in bargaining. The evidence from psychology studies, e.g. Poucke and Buelens (2002), is that players who begin bargaining with high demands are more likely to end up with a higher payoff. This is also known in psychology as anchoring effect (e.g. Kahneman, 1992). We regressed final payoff for initial demands when reaching an agreement in the 2 nd or later trial and found a significant and positive correlation between the two variables (see the third and fourth columns of Table 5). 
Table 5: Linear regressions on demand level and earnings when agreed at trial $t>1$

\begin{tabular}{|c|c|c|c|c|}
\hline \multirow[t]{2}{*}{ Regression } & $(5)$ & $(6)$ & $(7)$ & $(8)$ \\
\hline & \multicolumn{2}{|c|}{ Demand $d_{i}^{t}$} & \multicolumn{2}{|c|}{ Agreed payoff $\mid t>1$} \\
\hline Variables & $c_{i}=25$ & $c_{i}=175$ & $c_{i}=25$ & $c_{i}=175$ \\
\hline$T=5$ & $\begin{array}{c}11.65^{* * *} \\
(4.203)\end{array}$ & $\begin{array}{l}-2.459 \\
(5.436)\end{array}$ & $\begin{array}{l}1.757 \\
(2.890)\end{array}$ & $\begin{array}{c}8.935^{* * *} \\
(3.069)\end{array}$ \\
\hline Protocol P & $\begin{array}{l}-0.984 \\
(7.788)\end{array}$ & $\begin{array}{c}-0.0464 \\
(11.19)\end{array}$ & $\begin{array}{l}-9.127^{*} \\
(5.215)\end{array}$ & $\begin{array}{l}1.895 \\
(3.942)\end{array}$ \\
\hline Protocol D & $\begin{array}{c}0.803 \\
(7.710)\end{array}$ & $\begin{array}{c}26.31^{* *} \\
(11.11)\end{array}$ & $\begin{array}{l}-0.182 \\
(5.421)\end{array}$ & $\begin{array}{c}5.557 \\
(4.168)\end{array}$ \\
\hline Trial & $\begin{array}{c}-22.58^{* * *} \\
(2.220)\end{array}$ & $\begin{array}{c}-31.57^{* * *} \\
(2.913)\end{array}$ & & \\
\hline$(T=5) \times$ Trial & $\begin{array}{c}6.305^{* * *} \\
(2.078)\end{array}$ & $\begin{array}{c}13.86^{* * *} \\
(2.688)\end{array}$ & & \\
\hline Protocol P $\times$ Trial & $\begin{array}{c}-4.530^{* *} \\
(2.206)\end{array}$ & $\begin{array}{c}0.173 \\
(2.869)\end{array}$ & & \\
\hline Protocol D × Trial & $\begin{array}{l}-1.901 \\
(2.094)\end{array}$ & $\begin{array}{c}-5.592^{* *} \\
(2.764)\end{array}$ & & \\
\hline 1st trial own demand $\left(d_{i}^{1}\right)$ & & & $\begin{array}{l}0.183^{* * *} \\
(0.0359)\end{array}$ & $\begin{array}{l}0.117^{* * *} \\
(0.0234)\end{array}$ \\
\hline 1st trial opponent demand $\left(d_{-i}^{1}\right)$ & & & $\begin{array}{c}-0.163^{* * *} \\
(0.0227)\end{array}$ & $\begin{array}{c}-0.172^{* * *} \\
(0.0309)\end{array}$ \\
\hline $5 \rightarrow 3$ & $\begin{array}{c}5.506 \\
(5.348)\end{array}$ & $\begin{array}{c}3.695 \\
(7.993)\end{array}$ & $\begin{array}{l}7.719^{*} \\
(4.331)\end{array}$ & $\begin{array}{l}-1.894 \\
(3.297)\end{array}$ \\
\hline Round & $\begin{array}{l}1.608^{*} \\
(0.836)\end{array}$ & $\begin{array}{c}4.898^{* * *} \\
(1.078)\end{array}$ & $\begin{array}{c}0.492 \\
(1.265)\end{array}$ & $\begin{array}{c}2.837^{* *} \\
(1.358)\end{array}$ \\
\hline Constant & $\begin{array}{c}357.6^{* * *} \\
(7.007)\end{array}$ & $\begin{array}{c}382.6^{* * *} \\
(9.910)\end{array}$ & $\begin{array}{c}299.9^{* * *} \\
(17.67)\end{array}$ & $\begin{array}{c}330.9^{* * *} \\
(16.43)\end{array}$ \\
\hline Observations & 1,423 & 1,423 & 355 & 355 \\
\hline Number of subjects & 144 & 144 & 136 & 135 \\
\hline Number of groups & 36 & 36 & 36 & 36 \\
\hline
\end{tabular}

Notes: See the notes of Table 4 for the specification of the regression models. 
We also checked the difference in the demand levels between players with the high and low conflict payoffs (see Table E.3 of online appendix). In protocol D, the difference increases by 26.89 as the high conflict payoff type increases the demand level.

Finding (d), that the amount of concession is larger for low conflict payoff players in protocol $\mathrm{P}$ rather than protocol $\mathrm{S}$, can be attributed to less chances of "no concession", Finding (a) of Regression (1): Again the evidence contradicts our conjecture that players being aware of not yet having agreed are more emotionally aroused.

Nevertheless, the outlined differences in demand levels between 3 protocols are too minor to impact on frequency of conflict, efficiency or (in)equal if agreements (see Result 1).

\subsection{Demand levels when bargaining ends}

As a further test for different causes of conflict, we compare between protocols distributions of last relevant demands by bargaining pairs which failed to agree. Using the Kruskal-Wallis test, as for agreements, distributions of last conflict demands do not differ significantly between protocols. Finally, a categorization of agreements into one of the categories, generous, equal split, in-between, mid-point, cheeky and selfish; also does not reveal any differences between protocols, except that in D high conflict types are initially reluctant to go for the equal split. More specifically, denoting the relevant demand of a high- and low type of an agreeing pair by $d_{25}$ and $d_{175}$ respectively, categories are defined as follows: generous: $d_{25}<250, d_{175}<325$; mid-point: $d_{25}=250, d_{175}=400$; in-between: $250<d_{25}<325,325<d_{175}<400$; equal split: $d_{25}=d_{175}=325$; cheeky: $325<d_{25}<475,400<d_{175}<625$; selfish: $d_{25} \geq 475, d_{175} \geq 625$. Categorization is performed individually. If we depict agreement payoffs in the plane by points $\left(d_{i}, d_{j}\right)$, where $i, j$ are defined by conflict payoffs $c_{i}=25$ and $c_{j}=175$, then $79 \%$ of all agreements lie in the triangular region between mid-point $(250,400)$, equal split $(325,325)$, and $(250,325)$, and $58 \%$ of all agreements grant the low type exactly 325 and $75 \%$ give 
one party exactly 325. All agreements yield each party at least its conflict payoff, and there is no conflict in line with a pure-strategy Nash equilibrium.

Result 6: In spite of the considerable asymmetry in conflict payoffs equal payoff shares, i.e. payoffs with 325 for at least one party, are observed very often (in $75 \%$ of all agreements).

\subsection{Alternation}

The experimental protocols do not impose alternation but participants may voluntarily try to take turns in conceding. To explore this we introduce a weak measure of intended alternation which is applicable to all protocols: define a concession of participant $i$ at trial $t$, denoted by $k_{i}^{t}$, as the difference in demands between two trials, and the first concession as the difference between the initially available surplus and the first submitted demand. More specifically, $k_{i}^{1}=650-c_{j}-d_{i}^{1}$ for $i \neq j$ and $k_{i}^{t}=d_{i}^{t-1}-d_{i}^{t}$ for $t>1$. We focus on cases with at least three demands and speak of an intended alternation if, for example $k^{1} \leq k^{2} \geq k^{3} \leq k^{4}$ or $k^{1} \geq k^{2} \leq k^{3} \geq k^{4}$ with at least two consecutive relations being strict. Thus, for example $k^{1}=k^{2}=k^{3}>k^{4}=k^{5}$ is not considered as an intended alternation, whereas $k^{1}=k^{2}<k^{3}>k^{4}=k^{5}$ is.

Table 6 reports the share of observations satisfying this alternation condition, for all cases with at least three demands, by protocol and deadline $T$. Despite the measure being fairly weak, only between $4.17 \%$ and $46.25 \%$ of cases indicate intended alternation. In the majority of all cases we can not confirm intended alternation.

Table 6: Share of intended alternation

\begin{tabular}{lll}
\hline Protocol & $T=3$ & $T=5$ \\
\hline $\mathrm{S}$ & $23.44 \%$ & $4.17 \%$ \\
$\mathrm{P}$ & $46.25 \%$ & $16.33 \%$ \\
$\mathrm{D}$ & $31.15 \%$ & $18.18 \%$ \\
\hline
\end{tabular}




\section{Conclusions}

Quite surprisingly, we are unable to find any effects of dynamic interaction on concession bargaining and its outcomes. This holds irrespective of whether we compare two different representations of the same game ( $\mathrm{S}$ vs. $\mathrm{P}$ ) or the more complex game (D), which allows truly dynamic and richer interaction. This finding confirms other null results of protocol on bargaining behavior (see, for example, Brandts and Charness, 2011, or the final section of Fischer and Güth, 2012). Concluding that behavior in the dynamic game is indistinguishable from the other protocols may seem comforting for bargaining theory as (strict) equilibrium theory makes the same broad (set) predictions, irrespective of protocol.

We observe instead the effect of time horizon on concession-making. A longer time horizon increases the frequency of no concession and decreases the size of concessions even when players concede. This result is consistent with the evidence from previous studies (see e.g. the meta-analysis by Stuhlmacher et al., 1998) that a shorter time horizon enhance concession-making and cooperation. As for the final outcome, however, we find the more conflict in case of the longer time horizon, which is the opposite finding of Karagözoğlu and Kocher (2015) in their unstructured bargaining experiment. The difference between their results and ours can be ascribed to the relatively long time horizon in Karagözoğlu and Kocher, and to the absence of the rule of ending the game in case of no concession by either parties.

We confirm the strong focus of behavior on equal payoff shares (see the early contributions by Homans, 1961, and for later more detailed discussion of equity theory Carrell and Dittrich, 1978). Whereas equity theory argues that fairness is focal and desirable, also in economics, one can allow for trade-off relationships between equity and own monetary concerns (see Kagel and Levin, 2009, for a recent review). This explains why aiming at the split-the difference solution or something nearby appears to be the best 
predictor of behavior irrespective of protocol. At the same time, however, we observe a significant number of pairs ending up with conflicts or an inefficient agreement. This can be theoretically explained as resulting from mixed strategy equilibrium play ${ }^{22}$. Mixed strategy equilibria are clearly payoff dominated by and less focal than strict equilibria such as equal surplus or payoff sharing ${ }^{23}$.

Finally, while alternation has great appeal and is often seen a natural feature of negotiations, our data do not confirm this. In spite of some cases of intended alternation, this only covers a fairly small share of observations. In our positional and dynamic protocols these might be due to dynamically reacting to the other's behavior.

The invariance bargaining protocol is comforting for the institutional design of bargaining and negotiation rules. Furthermore, it would be seen as good news that outcomes do not improve by longer bargaining procedures and that, the contrary, a longer time horizon increases conflict due to the increasing stubbornness of the stronger party. In view of our findings we do not have to return to bazar-like negotiations rules even when modern information technology would allow to apply them in the global economy. Therefore, the fact that real world bargaining is often very time consuming may be due to incomplete information about the other party's bargaining position or due to ritually displaying toughness, e.g. by conceding minimally or not at all (hoping the other party will concede).

\section{Notes}

1. We abstract from endogenous threats which, according to Nash (1953), are strategically chosen before trying to reach an agreement, an at least debatable timing assumption. This is done by assuming exogenously given conflict payoffs as in Nash (1950).

2. In case of complete information actually an agreement is reached immediately, i.e. for alternating to be an equilibrium outcome one has to refer to incomplete information bargaining (see Rubenstein, 1985, and closer to our setup with simultaneous demands Harsanyi and Selten, 1972). 
3. Our approach is similar to the bargaining study of Harsanyi and Selten (1972), who generalize the Nash bargaining solution to situations with incomplete information.

4. Anticonflicts are agreements whose demands do not add up to what is available.

5. In line with much of the literature but contrary to ultimatum bargaining, all experimental protocols allow for anti-conflict in the sense of agreements on sharing less than is available.

6. Harsanyi and Selten (1972) and Rubinstein (1985) are pioneering studies of incomplete information bargaining.

7. In case of agreement the proposer earns the pie size minus the accepted offer to the responder what excludes anticonflict agreements which are actually observed in all our three protocols.

8. Fischer et al. (2006) connect the two games as border cases of a one-parameter game class and explore game-theoretically and experimentally what happens when this parameter changes.

9. For every $\tau$ the conceding player may be the same, another one, or both.

10. By "within subjects" we mean that every participant experienced both conditions, $T=3$ and $T=5$. "Between subjects" implies that every participant only played one of the three protocols.

11. A learning study would require many more repetitions of the various games, that might be the focus of future research.

12. No one interacted with anyone more than once.

13. The exchange rate was 1 point $=0.01 €$.

14. Field of studies from the following areas: $14.9 \%$ social sciences, $13.5 \%$ Business, $11.8 \%$ Humanities, 11.5\% Teaching studies, 9.4\% natural sciences, 7.3\% Human Health, 6.3\% Law, 5.6\% engineering, 9.7\% other, remainder unreported.

15. Socio-demographic characteristics: length of studies, income, and experience with laboratory experiments. Unfortunately we only have partial observations since answering such questions is voluntary.

16. We thank an anonymous referee for suggesting the use of the multiple-comparison test. 
17. When both parties do not concede in the last trial, we categorize the case as conflict due to no concession.

18. Figure E.3 of the online appendix is the same diagram with non-cumulative incidence over trial.

19. We tried non-parametric analysis as well (see Table E.2 of the online appendix), with evidence only for high conflict types that the longer time horizon renders conceding less likely. This could be due to the weaker statistical power.

20. We select this interval as the mean demand level when the high conflict payoff player makes no concession is approximately 350 (see Table E.2 of the online appendix).

21. As indicated before we wanted to rule out minor ("peanut") concessions in favor of substantial sacrifices, especially when not only conceding once before agreeing.

22. Note, however, that mixed strategies might involve mixing on various stages of concession-making, that renders the game more complex and cognitively demanding.

23. This is in line with equilibrium selection theories (see Nash, 1950, 1953 and Harsanyi and Selten, 1972) which consider strict equilibria as initial candidates when resolving strategic uncertainty.

\section{References}

Anbarci, N. and N. Feltovich (2013). How sensitive are bargaining outcomes to changes in disagreement payoffs? Experimental Economics 16(4), 560 - 596.

Anbarci, N. and N. Feltovich (2014). How fully do people exploit their bargaining position? The effects of bargaining institution and the $50-50$ norm.

Benjamini, Y. and Y. Hochberg (1995). Controlling the false discovery rate: a practical and powerful approach to multiple testing. Journal of the royal statistical society. Series B (Methodological), 289-300.

Bolton, G. E. and E. Karagözoğlu (2016). On the influence of hard leverage in a soft leverage bargaining game: The importance of credible claims. Games and Economic Behavior 99, $164-179$. 
Bosman, R., J. Sonnemans, and M. Zeelenberg (2001). Emotions, rejections, and cooling off in the ultimatum game. Creed working paper, Amsterdam School of Economics Research Institute (ASE-RI).

Brandts, J. and G. Charness (2011). The strategy versus the direct-response method: A first survey of experimental comparisons. Experimental Economics 14(3), 375 - 398.

Carrell, M. R. and J. E. Dittrich (1978). Equity theory: The recent literature, methodological considerations, and new directions. Academy of Management Review 3(2), 202-210.

Du Caju, P., E. Gautier, D. Momferatou, and M. Ward-Warmedinger (2008). Institutional features of wage bargaining in 23 European countries, the US and Japan. Working Paper Series 0974, European Central Bank.

Felli, C., W. Güth, E. Mata-Pérez, and G. Ponti (forthcoming). Ultimatum concession bargaining: An experimental study. Journal of Conflict Resolution.

Fischbacher, U. (2007). Z-tree: Zurich Toolbox for Ready-made Economic Experiments. Experimental Economics 10(2), $171-178$.

Fischer, S. and W. Güth (2012). Effects of exclusion on acceptance in ultimatum games. Journal of Economic Psychology 33(6), 1100 - 1114.

Fischer, S., W. Güth, W. Muller, and A. Stiehler (2006). From ultimatum to nash bargaining: Theory and experimental evidence. Experimental Economics 9(1), 17 33.

Fischer, S., W. Güth, and K. Pull (2007). Is there as-if bargaining? Journal of SocioEconomics 36(4), $546-560$.

Greiner, B. (2015). Subject pool recruitment procedures: Organizing experiments with ORSEE. Journal of the Economic Science Association 1(1), 114-125. 
Grimm, V. and F. Mengel (2011). Let me sleep on it: Delay reduces rejection rates in ultimatum games. Economics Letters 111(2), 113 - 115.

Harsanyi, J. C. (1956). Approaches to the bargaining problem before and after the theory of games: A critical discussion of Zeuthen's, Hicks', and Nash's theories. Econometrica 24, $144-157$.

Harsanyi, J. C. and R. Selten (1972). A generalized Nash solution for two-person bargaining games with incomplete information. Management Science 18(5-part-2), 80-106.

Homans, G. C. (1961). Social behavior: Its elementary forms. Harcourt, Brace \& World.

Kagel, J. H. and D. Levin (2009). Common value auctions and the winner's curse. Princeton University Press.

Kahneman, D. (1992). Reference points, anchors, norms, and mixed feelings. Organizational Behavior and Human Decision Processes 51(2), 296 - 312.

Karagözoğlu, E. and M. Kocher (2015). Bargaining under time pressure. CESifo Working Paper Series 5685, CESifo Group Munich.

Kohlberg, E. and J.-F. Mertens (1986). On the strategic stability of equilibria. Econometrica 54(5), $1003-1037$.

Levinson, H. M. (1966). Determining forces in collective wage bargaining, Volume 3. Wiley.

Nash, J. F. (1950). The bargaining problem. Econometrica 18, 155 - 162.

Nash, J. F. (1953). Two-person cooperative games. Econometrica 21, 128 - 140.

Neumann, J. v. and O. Morgenstern (1944). Theory of games and economic behavior, Volume 60. Princeton university press Princeton. 
Oechssler, J., A. Roider, and P. W. Schmitz (2015). Cooling off in negotiations: Does it work? Journal of Institutional and Theoretical Economics 171(4), 565 - 588.

Poucke, D. V. and M. Buelens (2002). Predicting the outcome of a two-party price negotiation: Contribution of reservation price, aspiration price and opening offer. Journal of Economic Psychology 23(1), $67-76$.

Rubinstein, A. (1982). Perfect equilibrium in a bargaining model. Econometrica 50(1), $97-109$.

Sauermann, H. (1967). Contributions to experimental economics, vol I. Tubingen, Mohr.

Schotter, A., W. Zheng, and B. Snyder (2000). Bargaining through agents: An experimental study of delegation and commitment. Games and Economic Behavior 30(2), $248-292$.

Stuhlmacher, A. F., T. L. Gillespie, and M. V. Champagne (1998). The impact of time pressure in negotiation: A meta-analysis. International Journal of Conflict Management 9(2), 97-116.

Zeuthen, F. (1930). Problems of monopoly and economic warfare. G. Routledge \& sons, ltd.

Zizzo, D. J. (2004). The neuroeconomics of anger. Homo Oeconomicus 21, 473-494.

Zizzo, D. J. (2008). Anger and economic rationality. Journal of Economic Methodology $15(2), 147-167$. 


\section{Online Appendix: Concession Bargaining}

An Experimental Comparison of Protocols and Time Horizons

\section{Contents}

A Experimental instructions 1

B Control questions 3

C Results of control questions 3

D Screenshots of the experiment 4

E Additional figures and tables $\quad 8$

\section{A Experimental instructions}

This section gives the experimental instructions translated from [name of language removed] Paragraphs which differed between protocols and $T$ are indicated accordingly.

\section{General Instructions}

Note: In the interest of a concise text we exclusively use the masculine gender despite describing gender-free aspects.

Welcome and thank you for taking part in this experiment.

Please read the following instructions carefully. If you have any questions, please raise your hand and one of us will come to help.

Instructions are identical for all participants. The experiment consists of four rounds. Rounds 1 and 2 are identical to each other, as are rounds 3 and 4 . You will first receive instructions for rounds 1 and 2 only. In every round you can earn money. How much money you earn depends on your own decisions, decisions made by other participants and a move of chance.

Your total income is the sum of earnings for all rounds. In the experiment, money will be denoted in "points". Each point will be worth $€ 0.01$. In addition, you will be paid a show-up fee of $€ 2.50$ for having shown up on time plus $€ 2.50$ for participation. You will receive your entire earnings at the end of the experiment anonymously in cash.

At the beginning of the experiment a move of chance will assign one of two roles - A and B to you. You will interact in this role during the entire experiment. One half of participants will decide in role $\mathrm{A}$ and the other half will decide in role $\mathrm{B}$.

In every round one participant A interacts with one participant B. The combination of participants A and B changes at every round, such that no one interacts with someone else more than once. 


\section{Instructions for rounds 1 and 2}

\section{Decisions in each round}

Participants A and B can allocate 650 points between each other. To do so, both participants $-\mathrm{A}$ and $\mathrm{B}$-must indicate how many points they claim for themselves. Whenever the sum of points claimed by A and B is smaller or equal to 650, we speak of an AGREEMENT. If A and $\mathrm{B}$ should not find an agreement at the end of a round, we speak of a disagreement.

How to state a claim

Each round consists of at most 3[5] trials. At each trial both participants can state a claim of points to the other participant. This is done by entering the claimed number of points into the appropriate field and by clicking the button "confirm". Before confirming your entry you can change your decision as often as you wish, but once you have confirmed it your entry is binding.

Both participants submit their claims simultaneously not knowing how many points the other participant claims. Once both have entered and confirmed their claims, the trial ends. Please note that in comparison to the previous trial, you cannot increase your claim. You can either leave your claim unchanged or decrease it by at least 25 points.

End of a round and your payment

If both participants found an AGREEMENT at the end of the last trial, then each obtains the number of points he claimed. If both found an agreement before the last trial, then the round ends with this trial and each obtains the number of points he claimed.

If at the end of the last trial both participants remain in DISAGREEMENT, then participant A obtains 25 points and participant B obtains 175 points.

If at any trial after the first one, none of the two participants reduces his claim in comparison to the previous trial, then the interaction ends with this trial. Participant A then obtains 25 and participant B 175 points.

At the end of each trial

Protocol $S$ : After each trial, participants will neither be informed about how much the other participant claimed, nor whether the round already ended. Only after both participants have submitted their claims FOR ALL TRIALS, each participant will be informed which trial was decisive and how many points the other participant claimed in all trials up to the decisive one.

Protocol P: After each trial, participants will not be informed about how much the other participant claimed. They will only be informed about whether there will be another trial. Only after both participants have submitted their claims FOR ALL POSSIBLE TRIALS up to the decisive one, each participant will be informed how many points the other participant claimed in all relevant trials.

Protocol D: After each trial, participants will be informed about how many points the other participant claimed and whether there will be another trial before the end of the round.

\section{Instructions for rounds 3 and 4}

\section{Decisions in each round}

The implementation of rounds 3 and 4 is identical to that of rounds 1 and 2 except for the maximal number of trials which changes from $3[5]$ to $5[3]$. 


\section{B Control questions}

The control questions were implemented and zTree (Fischbacher, 2007). Participants had to indicate whether a statement was true or false. Whenever a statement was false, all were given the corrected statement.

Please indicate whether the following statements are TRUE or FALSE:

1. In the first round, $\mathrm{A}$ and $\mathrm{B}$ are given a maximum of $3[5]$ trials to allocate 650 points between each other.

- If answer was "TRUE": This is the correct answer.

- If answer was "FALSE": Your answer is wrong.

2. If in the first trial $\mathrm{A}$ and $\mathrm{B}$ altogether claim 500 points then the interaction ends and each participant obtains the amount he claimed.

- If answer was "TRUE": This is the correct answer.

- If answer was "FALSE": Your answer is wrong.

3. If at the first trial $\mathrm{A}$ and $\mathrm{B}$ altogether claim 700 points then the interaction ends and each participant obtains the amount he claimed.

- If answer was "TRUE": This is wrong. If at any trial prior to the final trial, A and B altogether claim 700 points then there is another trial.

- If answer was "FALSE": This is the correct answer.

4. If at the final trial $\mathrm{A}$ and $\mathrm{B}$ altogether claim 700 points then each participant obtains the amount he claimed.

- If answer was "TRUE": This is wrong. If at the final trial A and B altogether claim 700 points then the round ends in disagreement. Participant A receives 25 points and B obtains 175 points.

- If answer was "FALSE": This is the correct answer.

5. If at a trial after the first one and before the third [fifth], both participants do not reduce their claim in comparison to the previous trial, then the round continues with another trial.

- If answer was "TRUE": This is wrong. If at any trial after the first one both participants do not reduce their claim in comparison to the previous trial, then the round ends in disagreement with A receiving 25 points and B obtaining 175.

- If answer was "FALSE": This is the correct answer.

\section{Results of control questions}

Table C.1 reports the rate of correct answers for each control question. The rate for question 5 is significantly low. This implies that, while reading instructions, subjects had difficulty in understanding the rule of early conflict due to no concessions.

Hence we run the logistic regressions on no concessions and the answer to question 5 in order to check whether subjects did not understand the rule even after completing the control questions. We have two opposing hypothesis: 
Table C.1: Rate of correct answers

$\begin{array}{ll}\text { Q.1 } & 89.9 \% \\ \text { Q.2 } & 74.3 \% \\ \text { Q.3 } & 97.6 \% \\ \text { Q.4 } & 96.2 \% \\ \text { Q.5 } & 55.2 \%\end{array}$

Hypothesis C.1: A subject, who answers Q.5 incorrectly, is more likely to refuse conceding; Hypothesis C.2: A subject, who answers Q.5 incorrectly, is less likely to refuse conceding;

As shown in Section B, when subjects answer control questions incorrectly, they will see the feedback that reminds them the rule of our experiment again. Hence, we assume that all subjects, whether they answer the question correctly or incorrectly, understand the rule by the time the game begins.

Hypothesis C.1 is the case where subjects, whose answers to Q.5 are wrong, see the feedback, but they still do not understand the rule. Hypothesis C.2 considers another possibility that subjects, who do not understand the rule, answer question 5 at random. If their answers happen to be incorrect, then they see the feedback, otherwise they miss the opportunity to learn the rule again. Thus, subjects with wrong answers eventually the rule better. In either case, not realizing the risk of the early break ups may make subjects refuse to concede more often.

Table C.2 reports the results of logistic regressions on no concession, which correspond to Regressions (1) and (2) of the main text. We have added a new dummy variable for subjects, who answer question 5 wrongly. The variable is insignificant for both types of players, hence we reject hypothesis C.1 and C.2.

Finally, we also checked if players less likely to refuse concession if they experience early breakups (conflict before reaching the final trail $T$ ) in previous rounds. The dummy variable of the experience of disagreement before reaching the final trial $T$ in any previous rounds is introduced in the third and fourth columns of Table C.2. If the coefficient is negative, there is a possibility that there are players, who stop no concession because they understand the rule of the early breakups by reading the instructions not by reading the instructions but by experiencing it in the actual game. Of course, there can be an alternative explanation for the negative coefficient: subjects learn how their opponents are stubborn too from the experience of early breakups, then they become less likely to refuse concessions in the next round onwards. Nevertheless, Regressions (C.3) and (C.4) shows that the coefficients are negative but not significant, so we do not find the evidence.

\section{Screenshots of the experiment}

This section contains the screenshots of three protocols:

- Figure D.1 is the dynamic protocol. When both parties $i=1,2$ simultaneously choose $d_{i}^{t}$, both $i$ know all previous demands by other party $d_{-i}^{s}, s<t$. The information is provided in the bottom table. In the middle of the screen, the blue rectangular indicates the player's own demand in the current trial. The pale blue is the level of concession from the last trial. The pale red rectangular is the demand by the other player in the last trial.

- Figure D.2 is the positional order protocol. When both parties $i=1,2$ simultaneously choose $d_{i}^{t}$, both $i$ are aware of $d_{1}^{s}+d_{2}^{s}>650$ for all previous proposals, $s<t$. But both $i$ do 
Table C.2: Logistic regressions on no concession

\begin{tabular}{|c|c|c|c|c|}
\hline \multirow[t]{2}{*}{ Regression } & (C.1) & (C.2) & (C.3) & (C.4) \\
\hline & \multicolumn{2}{|c|}{ No concession } & \multicolumn{2}{|c|}{ No concession } \\
\hline Variables & $c_{i}=25$ & $c_{i}=175$ & $c_{i}=25$ & $c_{i}=175$ \\
\hline$T=5$ & $\begin{array}{c}0.737^{* * *} \\
(0.218)\end{array}$ & $\begin{array}{c}0.775^{* * *} \\
(0.229)\end{array}$ & $\begin{array}{c}0.725^{* * *} \\
(0.221)\end{array}$ & $\begin{array}{c}0.757^{* * *} \\
(0.227)\end{array}$ \\
\hline Protocol P & $\begin{array}{c}-0.885^{* *} \\
(0.360)\end{array}$ & $\begin{array}{l}-0.256 \\
(0.364)\end{array}$ & $\begin{array}{c}-0.902^{* *} \\
(0.375)\end{array}$ & $\begin{array}{l}-0.305 \\
(0.366)\end{array}$ \\
\hline Protocol D & $\begin{array}{l}-0.382 \\
(0.348)\end{array}$ & $\begin{array}{l}-0.309 \\
(0.373)\end{array}$ & $\begin{array}{l}-0.411 \\
(0.366)\end{array}$ & $\begin{array}{l}-0.353 \\
(0.375)\end{array}$ \\
\hline Trial & $\begin{array}{l}-0.200 \\
(0.123)\end{array}$ & $\begin{array}{l}-0.191 \\
(0.130)\end{array}$ & $\begin{array}{l}-0.213^{*} \\
(0.125)\end{array}$ & $\begin{array}{l}-0.182 \\
(0.129)\end{array}$ \\
\hline$d_{i}^{t-1}=325$ & $\begin{array}{c}2.527^{* * *} \\
(0.291)\end{array}$ & $\begin{array}{c}3.653^{* * *} \\
(0.346)\end{array}$ & $\begin{array}{c}2.548^{* * *} \\
(0.298)\end{array}$ & $\begin{array}{c}3.655^{* * *} \\
(0.346)\end{array}$ \\
\hline $325<d_{i}^{t-1} \leq 350$ & $\begin{array}{c}-0.00374 \\
(0.306)\end{array}$ & $\begin{array}{c}0.660^{* *} \\
(0.268)\end{array}$ & $\begin{array}{r}-0.0233 \\
(0.311)\end{array}$ & $\begin{array}{c}0.671^{* *} \\
(0.267)\end{array}$ \\
\hline $5 \rightarrow 3$ & $\begin{array}{l}-0.337 \\
(0.290)\end{array}$ & $\begin{array}{c}-0.647^{* *} \\
(0.302)\end{array}$ & $\begin{array}{l}-0.289 \\
(0.302)\end{array}$ & $\begin{array}{c}-0.747^{* *} \\
(0.297)\end{array}$ \\
\hline Round & $\begin{array}{l}-0.0647 \\
(0.0938)\end{array}$ & $\begin{array}{l}0.199^{* *} \\
(0.0991)\end{array}$ & & \\
\hline Wrong answer to Q. 5 & $\begin{array}{c}0.161 \\
(0.294)\end{array}$ & $\begin{array}{c}0.177 \\
(0.300)\end{array}$ & & \\
\hline Experience of early breakups & & & $\begin{array}{c}-0.681^{*} \\
(0.380)\end{array}$ & $\begin{array}{c}-0.0573 \\
(0.364)\end{array}$ \\
\hline Constant & $\begin{array}{c}-1.186^{* *} \\
(0.543) \\
\end{array}$ & $\begin{array}{c}-2.026^{* * *} \\
(0.556) \\
\end{array}$ & $\begin{array}{c}-1.176^{* *} \\
(0.479) \\
\end{array}$ & $\begin{array}{c}-1.364^{* * *} \\
(0.452)\end{array}$ \\
\hline Observations & 847 & 847 & 847 & 847 \\
\hline Number of subjects & 141 & 141 & 141 & 141 \\
\hline Number of groups & 36 & 36 & 36 & 36 \\
\hline
\end{tabular}

Notes: See the notes of Table 4 of the main text for the specification of the regression models. 
not know all previous demands by other party $d_{-i}^{s}, s<t$. Thus the pale red rectangular is hidden.

- Figure D.3 is the static protocol. When both parties $i=1,2$ simultaneously choose $d_{i}^{t}$, both $i$ know neither if they are yet to reach an agreement nor all previous demands by other party.

The feedback screen at the end of bargain is the same for all three protocols (see Figure D.4).

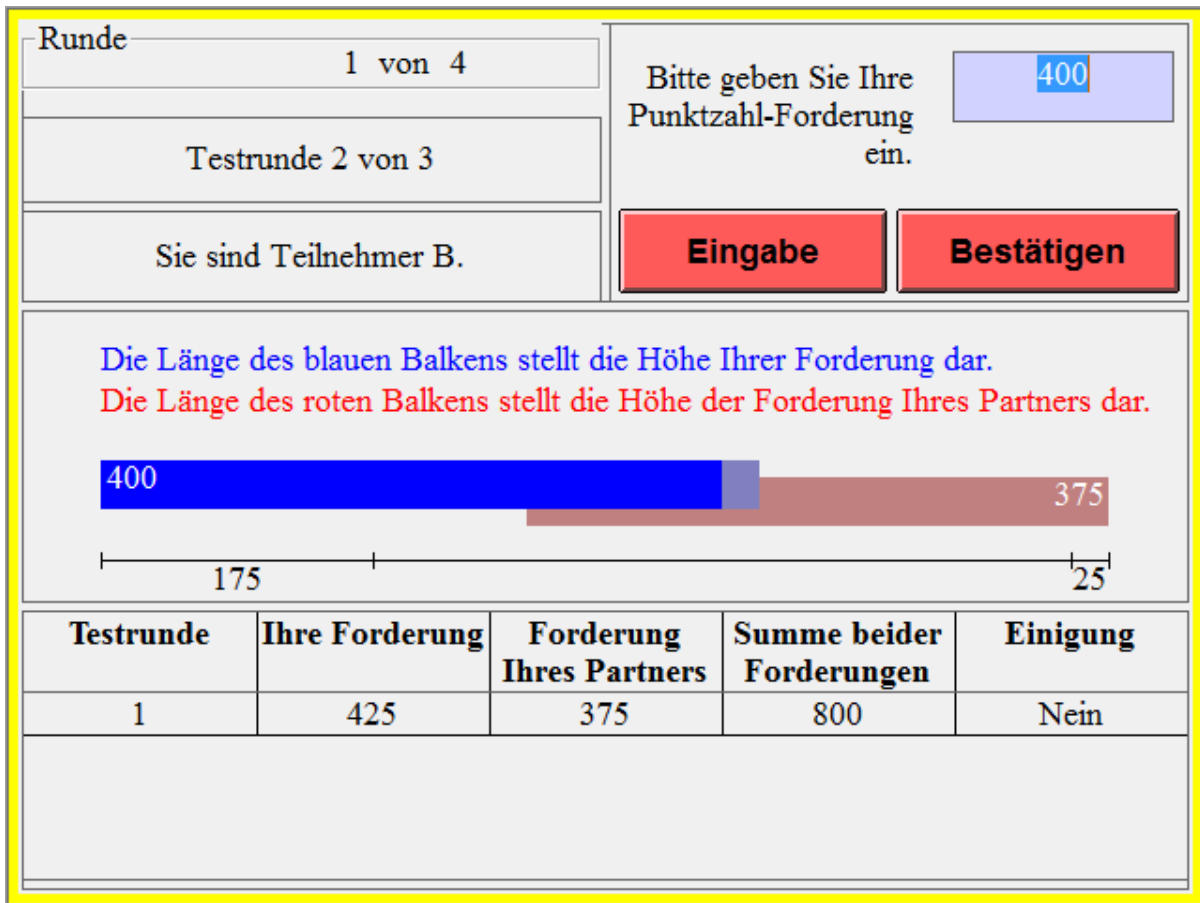

Figure D.1: Screenshot of the dynamic protocol 


\begin{tabular}{|c|c|c|}
\hline Runde & 1 von 4 & Bitte geben Sie Ihre \\
Punktzahl-Forderung \\
ein.
\end{tabular}

Die Länge des blauen Balkens stellt die Höhe Ihrer Forderung dar.

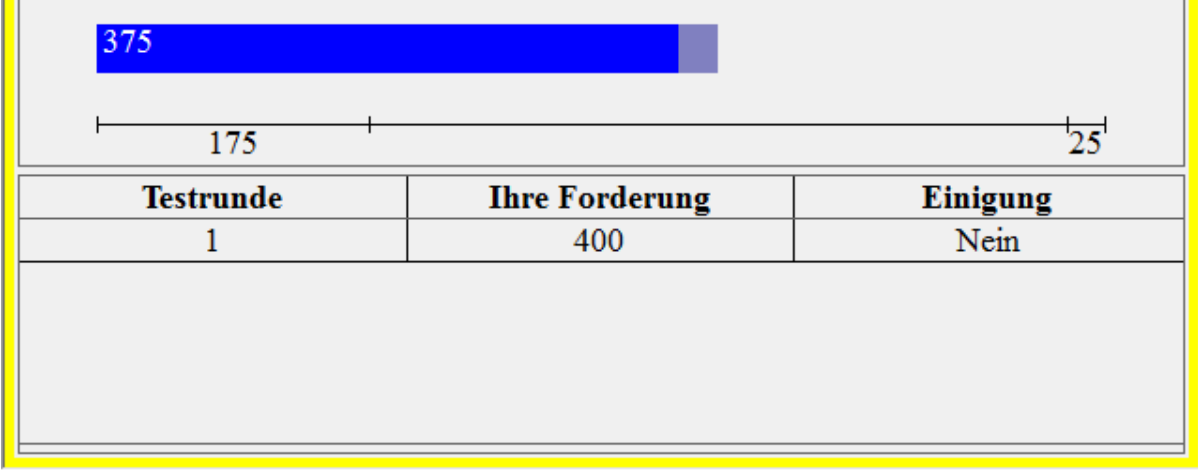

Figure D.2: Screenshot of the positional order protocol

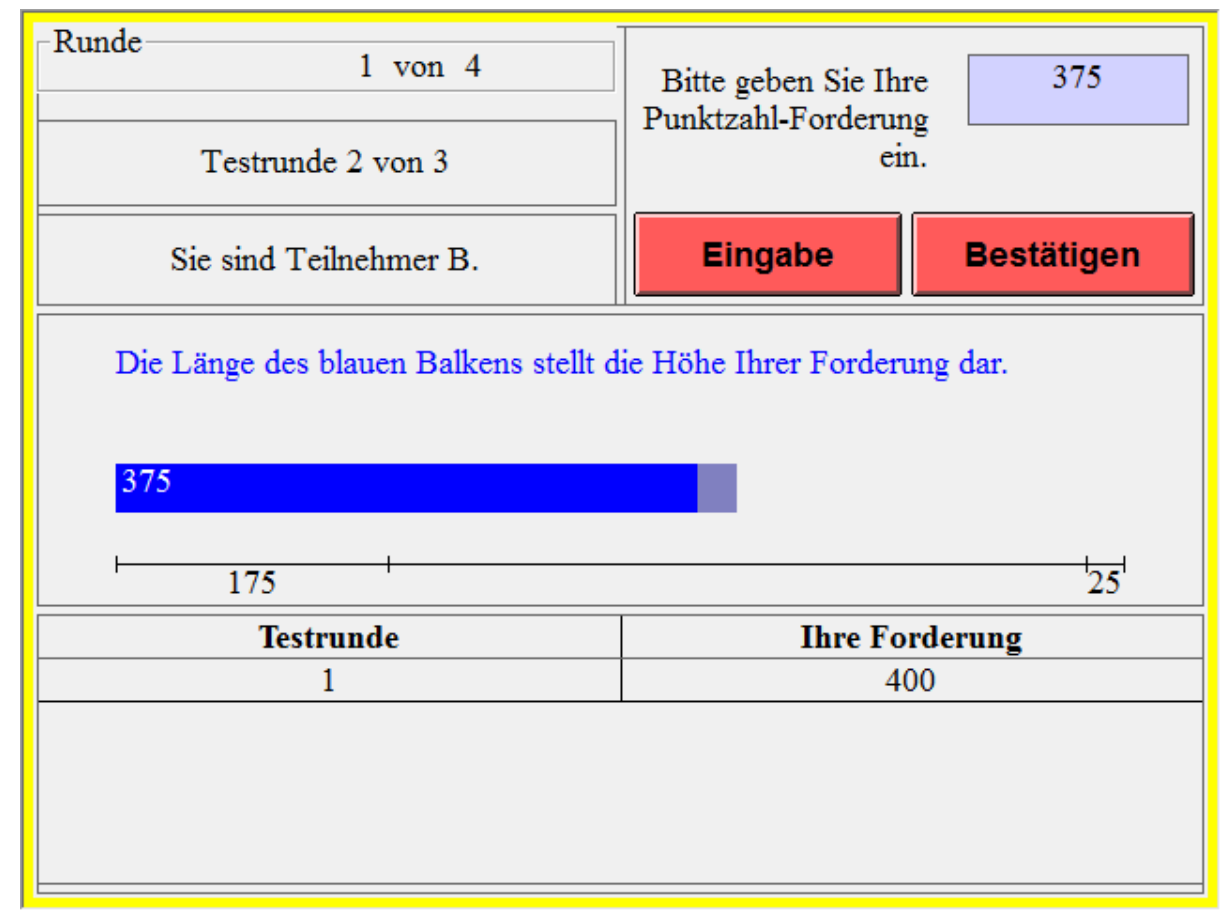

Figure D.3: Screenshot of the static protocol 


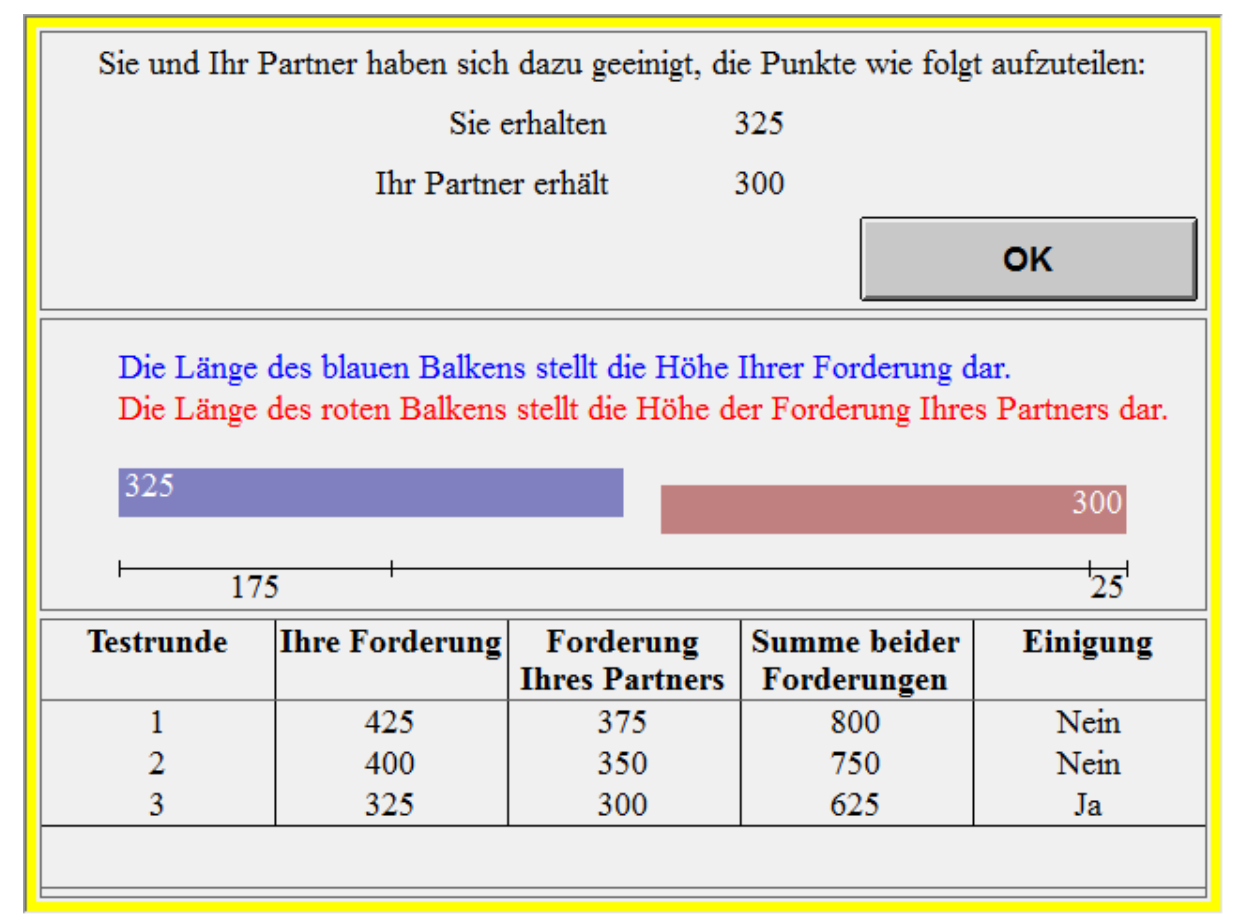

Figure D.4: Screenshot of feedback after bargaining

\section{E Additional figures and tables}
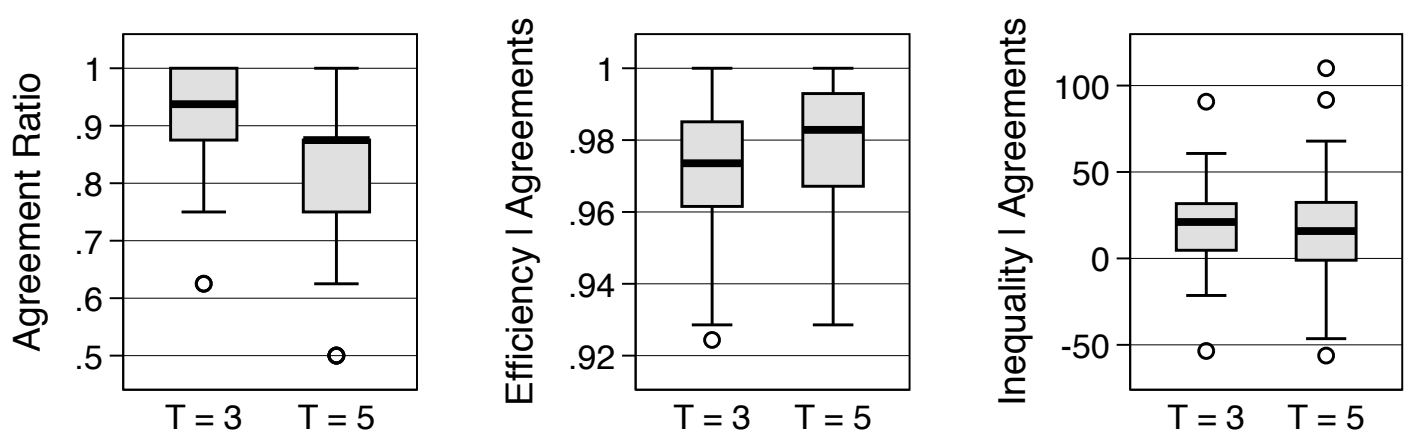

Figure E.1: Agreement ratio, efficiency and inequality by time horizon $T$

Notes: Each observation is the mean value at the group level. 


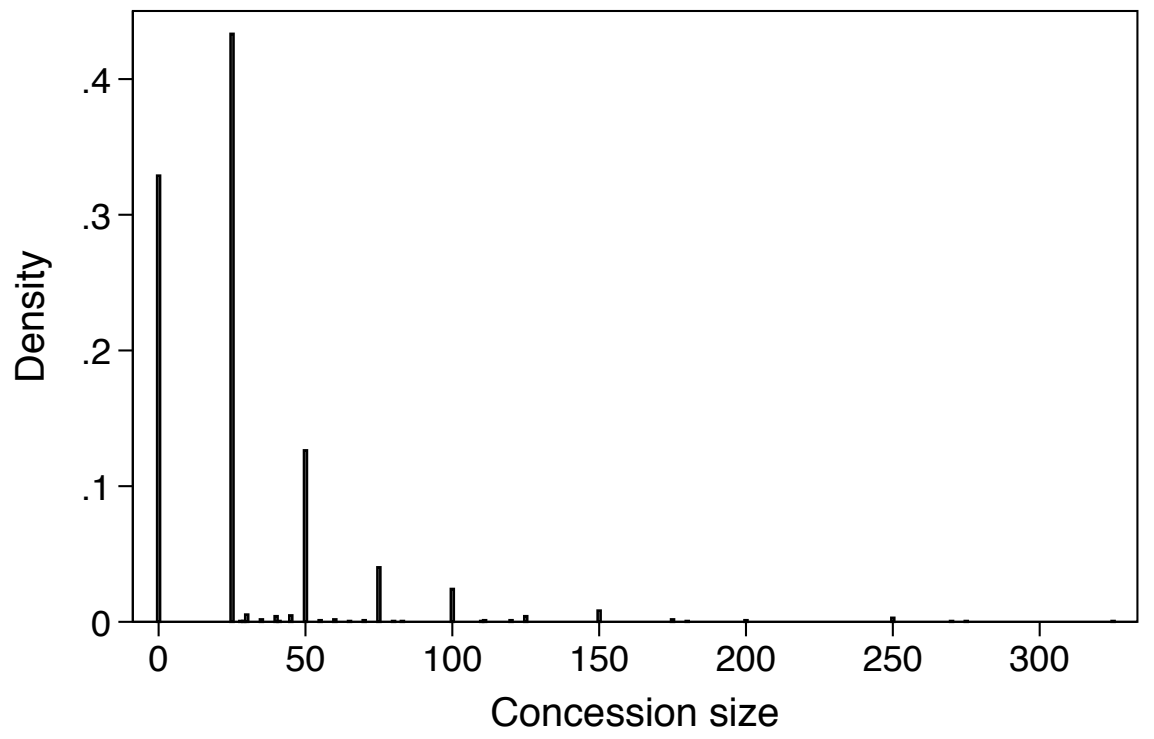

Figure E.2: Histogram of concession sizes

Notes: Each observation is the decision per trial per subject for $t>1$. For Protocol S, we exclude the observations of pairs that have finished bargaining.
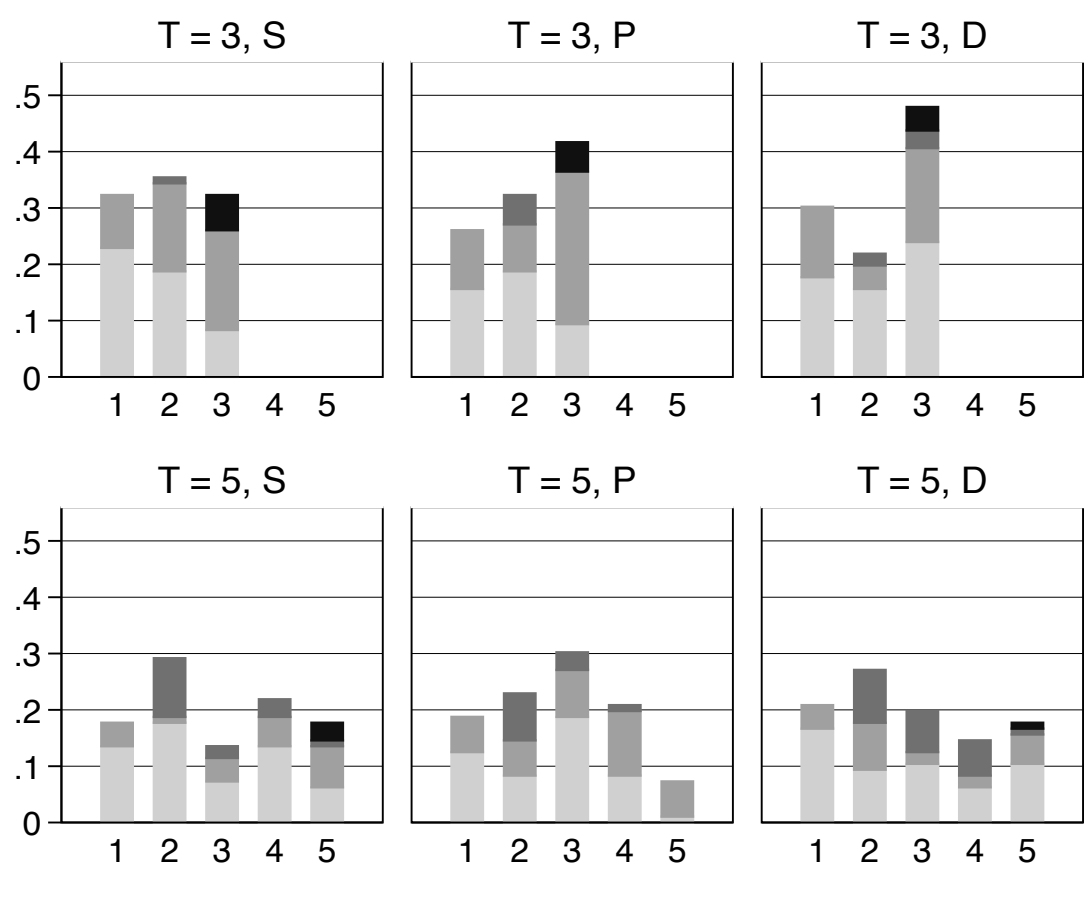

Trial

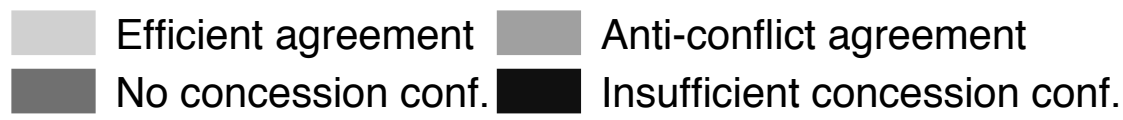

Figure E.3: Types of outcomes 


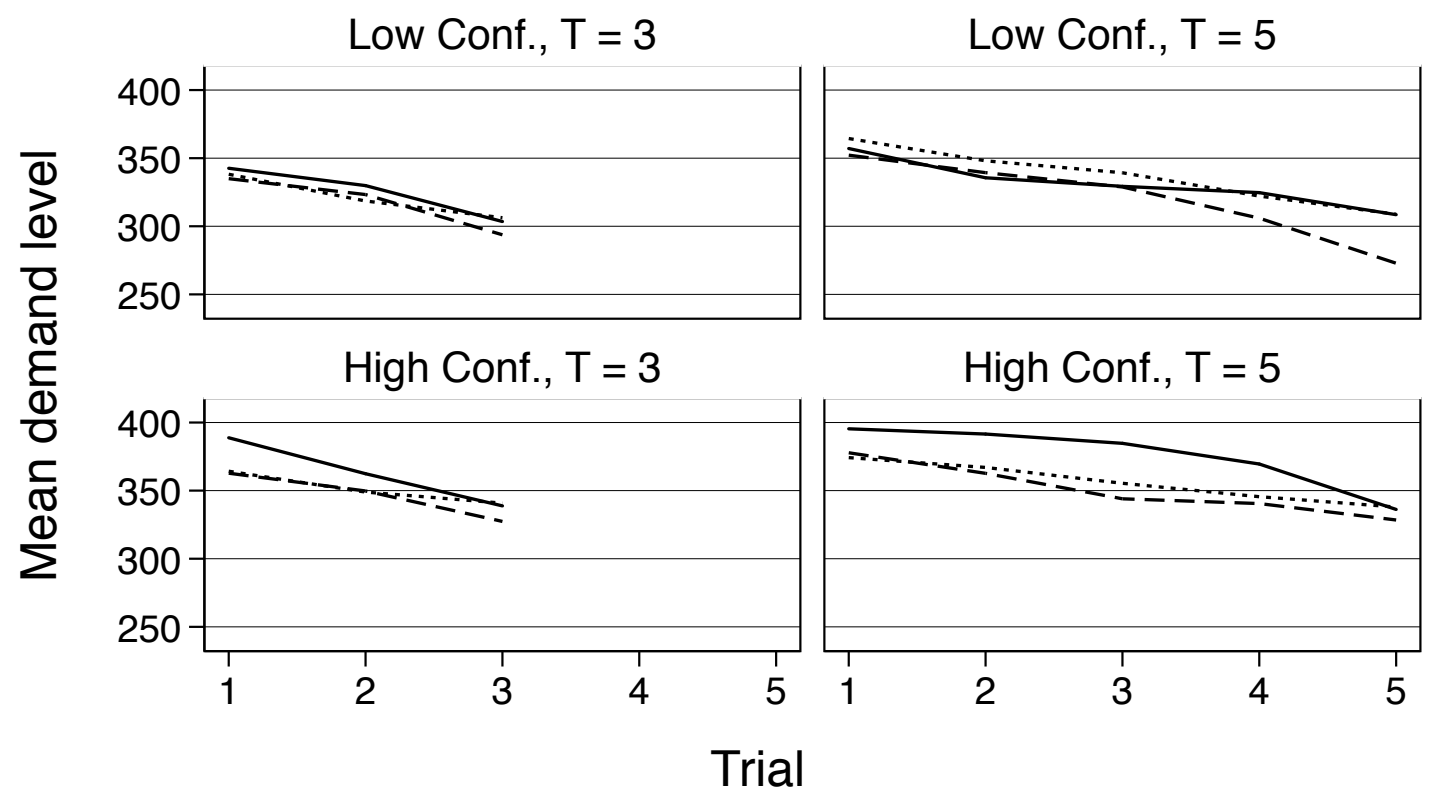

Dynamic ---- Positional-order ….... Static

Figure E.4: Mean demand levels by conflict payoff $c_{i}$ and time horizon $T$

Notes: For Protocol S, we exclude the observations of pairs that have finished bargaining. 
Table E.1: Regressions on agreement, efficiency and inequality

\begin{tabular}{|c|c|c|c|c|c|c|c|c|c|}
\hline \multirow[t]{2}{*}{ Regression } & (E.1) & (E.2) & (E.3) & (E.4) & (E.5) & (E.6) & (E.7) & (E.8) & (E.9) \\
\hline & \multicolumn{3}{|c|}{ Agreement } & \multicolumn{3}{|c|}{ Efficiency | Agreement } & \multicolumn{3}{|c|}{ Inequality | Agreement } \\
\hline Variables & $T=3$ & $T=5$ & Combined & $T=3$ & $T=5$ & Combined & $T=3$ & $T=5$ & Combined \\
\hline Protocol P & $\begin{array}{l}-0.487 \\
(0.877)\end{array}$ & $\begin{array}{c}0.647 \\
(0.501)\end{array}$ & $\begin{array}{c}0.237 \\
(0.402)\end{array}$ & $\begin{array}{l}-0.00346 \\
(0.00745)\end{array}$ & $\begin{array}{c}-0.00636 \\
(0.00851)\end{array}$ & $\begin{array}{l}-0.00461 \\
(0.00572)\end{array}$ & $\begin{array}{c}9.195 \\
(9.938)\end{array}$ & $\begin{array}{c}23.35 \\
(15.46)\end{array}$ & $\begin{array}{l}16.70^{*} \\
(8.759)\end{array}$ \\
\hline Protocol D & $\begin{array}{l}-0.192 \\
(0.906)\end{array}$ & $\begin{array}{l}-0.356 \\
(0.449)\end{array}$ & $\begin{array}{l}-0.319 \\
(0.380)\end{array}$ & $\begin{array}{c}0.00899 \\
(0.00743)\end{array}$ & $\begin{array}{l}-0.00694 \\
(0.00881)\end{array}$ & $\begin{array}{c}0.00168 \\
(0.00581)\end{array}$ & $\begin{array}{c}8.015 \\
(9.928)\end{array}$ & $\begin{array}{c}14.85 \\
(15.90)\end{array}$ & $\begin{array}{c}10.34 \\
(8.865)\end{array}$ \\
\hline$T=5$ & & & $\begin{array}{c}-0.974^{* * *} \\
(0.276)\end{array}$ & & & $\begin{array}{c}0.00513 \\
(0.00439)\end{array}$ & & & $\begin{array}{l}-0.629 \\
(5.540)\end{array}$ \\
\hline $5 \rightarrow 3$ & $\begin{array}{l}-0.938 \\
(1.256)\end{array}$ & $\begin{array}{c}0.627 \\
(0.769)\end{array}$ & $\begin{array}{c}0.136 \\
(0.328)\end{array}$ & $\begin{array}{c}-0.000794 \\
(0.0136)\end{array}$ & $\begin{array}{c}-0.0202 \\
(0.0139)\end{array}$ & $\begin{array}{c}-0.000538 \\
(0.00472)\end{array}$ & $\begin{array}{c}11.03 \\
(14.33)\end{array}$ & $\begin{array}{l}-11.77 \\
(19.49)\end{array}$ & $\begin{array}{l}-8.633 \\
(7.207)\end{array}$ \\
\hline Round & $\begin{array}{c}0.258 \\
(0.511)\end{array}$ & $\begin{array}{l}0.0542 \\
(0.329)\end{array}$ & $\begin{array}{l}-0.139 \\
(0.121)\end{array}$ & $\begin{array}{c}0.00701 \\
(0.00609)\end{array}$ & $\begin{array}{l}-0.00269 \\
(0.00587)\end{array}$ & $\begin{array}{c}0.00591^{* * *} \\
(0.00195)\end{array}$ & $\begin{array}{l}-3.918 \\
(5.899)\end{array}$ & $\begin{array}{c}5.379 \\
(7.201)\end{array}$ & $\begin{array}{l}4.634^{*} \\
(2.455)\end{array}$ \\
\hline Constant & $\begin{array}{c}3.965^{* * *} \\
(1.317)\end{array}$ & $\begin{array}{c}1.271 \\
(1.219)\end{array}$ & $\begin{array}{c}3.031^{* * *} \\
(0.531)\end{array}$ & $\begin{array}{c}0.953^{* * *} \\
(0.0110)\end{array}$ & $\begin{array}{c}0.998^{* * *} \\
(0.0220)\end{array}$ & $\begin{array}{c}0.958^{* * *} \\
(0.00699)\end{array}$ & $\begin{array}{c}16.83 \\
(12.00)\end{array}$ & $\begin{array}{l}-1.469 \\
(28.57)\end{array}$ & $\begin{array}{c}2.354 \\
(9.691)\end{array}$ \\
\hline Observations & 288 & 288 & 576 & 262 & 233 & 495 & 262 & 233 & 495 \\
\hline Number of subjects & 144 & 144 & 144 & 139 & 135 & 143 & 139 & 135 & 143 \\
\hline Number of groups & 36 & 36 & 36 & 36 & 36 & 36 & 36 & 36 & 36 \\
\hline
\end{tabular}

Notes: Each observation is the outcome per period per subject with the high conflict payoff. The regressions are three-level mixed models with random intercepts at both the session and the subject-within-session levels. Agreement is regressed with a logit model. Efficiency and inequality are regressed with linear models. The dummy variable " $5 \rightarrow 3$ " $=1$ if $T=5$ in the first two rounds, otherwise 0 . Standard errors in parentheses. Significance levels: ${ }^{* * *} p<0.01,{ }^{* *} p<0.05,{ }^{*} p<0.1$. 
Table E.2: Sign-rank tests on no concession rate and no concession demand level by time horizon $T$

\begin{tabular}{|c|c|c|c|c|c|c|c|c|c|c|}
\hline \multirow{3}{*}{$\begin{array}{l}\text { Conflict } \\
\text { Payoff }\end{array}$} & \multirow[b]{3}{*}{ Protocol } & \multicolumn{4}{|c|}{ No Concession Rate } & \multicolumn{5}{|c|}{ No Concession Demand Level } \\
\hline & & \multicolumn{2}{|l|}{ Mean } & \multirow[b]{2}{*}{$(N)$} & \multirow{2}{*}{$\begin{array}{l}p \text {-value } \\
\text { signrank }\end{array}$} & \multicolumn{2}{|l|}{ Mean } & \multicolumn{2}{|l|}{$(N)$} & \multirow{2}{*}{$\begin{array}{l}p \text {-value } \\
\text { signrank }\end{array}$} \\
\hline & & $T=3$ & $T=5$ & & & $T=3$ & $T=5$ & $T=3$ & $T=5$ & \\
\hline \multirow{4}{*}{25} & $\mathrm{~S}$ & 0.3511 & 0.3775 & $(12)$ & 0.8139 & 326.4 & 326.2 & $(12)$ & $(12)$ & 0.8427 \\
\hline & $\mathrm{P}$ & 0.2233 & 0.3179 & (12) & 0.3264 & 325.2 & 335.7 & (10) & $(12)$ & 0.1322 \\
\hline & $\mathrm{D}$ & 0.3932 & 0.4732 & $(12)$ & 0.3465 & 326.9 & 329.0 & $(12)$ & $(12)$ & 1.0000 \\
\hline & Combined & 0.3225 & 0.3895 & $(36)$ & 0.1717 & 326.2 & 330.3 & $(34)$ & $(36)$ & 0.3841 \\
\hline \multirow{4}{*}{175} & $\mathrm{~S}$ & 0.2520 & 0.4356 & $(12)$ & 0.0121 & 349.6 & 348.4 & (11) & $(12)$ & 0.3978 \\
\hline & $\mathrm{P}$ & 0.3073 & 0.3699 & (12) & 0.2393 & 357.5 & 354.4 & (12) & (12) & 0.7231 \\
\hline & $\mathrm{D}$ & 0.2494 & 0.3706 & (12) & 0.0309 & 344.7 & 374.2 & (11) & (11) & 0.0827 \\
\hline & Combined & 0.2696 & 0.3921 & $(36)$ & 0.0006 & 350.8 & 358.6 & $(34)$ & $(35)$ & 0.1855 \\
\hline
\end{tabular}

Notes: "No concession rate" means the probability that a player refuses to concede in a trial $t>1$. $p$-values are two-sided. Each observation is at 
Table E.3: Linear regression on the difference in the demand levels between players with the high and low conflict payoffs

\begin{tabular}{lc}
\hline Regression & $(\mathrm{E} .10)$ \\
\cline { 2 - 2 } Variables & $d_{175}^{t}-d_{25}^{t}$ \\
\hline$T=3$ & $17.20^{* *}$ \\
& $(7.781)$ \\
Protocol P & 5.690 \\
& $(13.60)$ \\
Protocol D & $26.89^{* *}$ \\
& $(13.46)$ \\
Trial & -2.205 \\
& $(2.901)$ \\
T $T=3) \times$ Trial & $-10.42^{* * *}$ \\
& $(3.845)$ \\
Protocol P $\times$ Trial & 0.00579 \\
& $(4.095)$ \\
Protocol D $\times$ Trial & -4.050 \\
& $(3.941)$ \\
$5 \rightarrow 3$ & -0.974 \\
& $(9.116)$ \\
Round & $3.972^{* *}$ \\
& $(1.542)$ \\
Constant & 9.206 \\
& $(11.65)$ \\
\hline Observations & 1,423 \\
Number of subjects & 144 \\
Number of groups & 36 \\
\hline
\end{tabular}

Notes: Each observation is the decision per trial per subjectwith the high conflict payoff. For Protocol S, we exclude the observations of pairs that have finished bargaining. The regressions are three-level mixed models with random intercepts at both the session and the subject-withinsession levels. Standard errors in parentheses. Significance levels: ${ }^{* * *} p<0.01,{ }^{* *} p<0.05,{ }^{*}$ $p<0.1$. 